\title{
A novel synthesis approach for WHENs
}

\section{considering unclassified process streams: From}

\section{LNG to above-ambient processes}

\author{
Viviani C. Onishi $^{a, b}{ }^{*}$, Natalia Quirante ${ }^{c}$, Mauro A. S. S. Ravagnani ${ }^{d}$ \\ José A. Caballero $^{c}$
}

${ }^{a}$ Department of Electrical and Computer Engineering, University of Coimbra, Polo II, Coimbra 3030-290, Portugal

${ }^{b}$ Institute for Systems Engineering and Computers at Coimbra - INESC Coimbra, Polo II, Coimbra 3030-290, Portugal

${ }^{c}$ Department of Chemical Engineering, University of Alicante, Ap. Correos 99, Alicante 03080, Spain

${ }^{d}$ Department of Chemical Engineering, State University of Maringá, Av. Colombo 5790, Maringá, PR 87020-900, Brazil

\section{* Corresponding author at.}

INESC Coimbra, Department of Electrical and Computer Engineering, University of Coimbra, Polo II, Coimbra 3030-290, Portugal.

E-mail addresses: viviani@deec.uc.pt; viviani.onishi@ua.es; (Viviani C. Onishi). 


\section{ABSTRACT}

Work and heat exchanger networks (WHENs) have recently drawn increasing attention due to their paramount importance in achieving energy savings. In this work, we introduce a novel mathematical model for the simultaneous optimization of WHENs synthesis considering unclassified process streams (i.e., streams whose classification as hot or cold cannot be defined a priori). Our innovative modelling approach combines mathematical programming techniques and the pinch location method aiming at obtaining an optimal WHEN design with minimal cost, while adjusting pressure and temperature levels of unclassified streams. We propose disjunctive operators for the selection of pressure manipulation equipment and streams identity classification depending on energy requirements and process operating conditions. In addition, our new model eliminates the need for assigning a specific route of pressure manipulation and classifying streams as high-pressure or low-pressure streams, which provides further flexibility to the system. Our modelling approach is also able to effectively deal with unknown inlet and outlet streams temperatures to reach any specific optimization goal. The model is implemented in GAMS and solved to global optimality through the minimization of the process total annualized cost. Besides improved computational performance, results from energy analysis reveal that streams classification during process optimization can be promising for both subambient and above-ambient applications. In the liquefied natural gas process, it reduces up to $89 \%$ the energy requirements when compared to literature records. 
Keywords: Simultaneous optimization; Generalized disjunctive programming (GDP); Pinch location method (PLM); Work and heat exchanger networks (WHENs); Variable temperatures. 


\section{Introduction}

Work and heat exchanger networks (WHENs) have become increasingly important for the field of process system engineering in the past few years. Growing research has distinctly shown that work and heat integration plays a critical role for reaching significant energy and cost savings, while enhancing system energy efficiency $[1,2]$. This is especially relevant for energy-intensive processes in oil refineries and cryogenic technology, such as the air separation, hydrogen liquefaction and production of liquefied natural gas (LNG) [3-5]. In the latter, very high energy consumption can be associated with compressing, expanding and cooling streams at subambient conditions [6,7]. In addition, the continuous rising in global energy demand, highly volatile energy prices, and stricter environmental policies towards the reduction of carbon emissions, have also boosted the development of work and heat recovery strategies for industrial processes.

The significance of work and heat integration as a strategic target to achieve more efficient processing technologies has been stressed by the pertaining literature. The concept of work exchanger networks (WENs) has been originally defined by Huang and Fan [8] in the late 1990s, as an analogy to the synthesis and optimization problems of heat exchanger networks (HENs) and mass exchanger networks (MENs). In this pioneering contribution, the authors have introduced fundamental insights for mechanical energy recovery between high-pressure (HP) and low-pressure (LP) streams, as well as an in-depth analysis of feasible stream matching to facilitate heuristic rules for the WEN design task. Remarkably, the authors have also anticipated that WENs could be combined to HENs in a simultaneous synthesis approach with potential economic implications. That combination of WENs and HENs has eventually prompted the birth of the so-called WHENs. 
Systematic integration of heat and power during the HEN optimization has been studied by Holiastos and Manousiouthakis [9]. In their work, the authors have provided important theoretical discussions, including the demonstration that the optimal heat and work network design may not always comply with the "appropriate placement" theory, as stated by Linnhoff et al. [10] and Townsend and Linnhoff [11,12]. Aspelund et al. [13] have proposed a heuristic-based approach—referred to as Extended Pinch Analysis and Design (ExPAnD)—for minimizing energy requirements in subambient processes. Later, Wechsung et al. [5] have developed a mathematical model based on the ExPAnD methodology for the optimal HENs synthesis, wherein heat integration can be enhanced by properly adjusting streams pressure levels. By identifying that the most appropriate placement of compression and expansion in the process may not always follow the “plus-minus" principle [14], the authors have proposed a specific pressure manipulation and heat exchange route of hot and cold streams, able to yield an increased exergy efficiency.

Onishi et al. [4] have used the route of pressure and temperature changes as proposed by Wechsung et al. [5] to formulate an optimization model for the simultaneous HENs synthesis with streams pressure manipulation. Through extensive energy and cost analyses, the authors have successfully demonstrated that the optimal placement of pressure manipulation equipment can significantly improve HENs costeffectiveness. Afterwards, the authors have extended this optimization model to address the retrofit of existing HENs, with simultaneous pressure recovery at subambient conditions [3]. Fu and Gundersen have proposed a set of fundamental thermodynamic theorems by revisiting the graphical methodology based on grand composite curves to evaluate the correct placement of expanders [15] and compressors [16] into HENs, when considering streams at above-ambient conditions. In Fu and Gundersen [17], the 
authors have shown the promising application of the latter studies for saving energy in carbon-capture processes.

Earlier efforts have also been made to develop systematic optimization approaches for the WENs synthesis. Razib et al. [18] have proposed an optimization model for the preliminary WENs synthesis, by using operating curves to identify potential HP and LP streams matches for work exchange via compressors and turbines running in the same single-shaft-turbine-compressor (SSTC). However, the authors have not considered the heat integration of streams, so that heaters and coolers are only used to adjust the streams outlet temperature. In Onishi et al. [19], the authors have introduced a mixed-integer nonlinear programming (MINLP)-based model for the optimal synthesis of integrated work-heat exchange networks, in which both WEN and HEN are simultaneously designed within a comprehensive superstructure. The authors have demonstrated that heat integration is decisive to significantly enhance the WEN energy efficiency, reducing capital and operating costs. The multi-objective optimization of WHENs has been addressed by Onishi et al. [2], for evaluating optimal trade-offs between economic and environmental system performance. Although preceding works have strongly contributed for the development of WHENs synthesis in the process system engineering field, mostly modelling approaches cannot ensure the global optimal solution.

Huang and Karimi [20] have replicated the work of Onishi et al. [19] by claiming that some improvements have been made mainly regarding the streams classification between no-pressure change and pressure change streams, as well as through an optimized selection of "end-heaters" and "end-coolers”. Regarding the latter, it should be noted that a very similar approach to optimize the selection of heaters and coolers at the end of the work exchange superstructure has been previously proposed by 
Razib et al. [18]. It is also noteworthy that the streams classification between nopressure change and pressure change is not strictly necessary, since if a stream does not require pressure-manipulation in a stage, a simple bypass can be considered instead, as shown in Onishi et al. [4,19,21].

While the results obtained by Huang and Karimi [20] are indeed better than preceding studies, their work presents a number of major inconsistencies. For instance, their modelling approach exhibits a flawed energy balance in SSTC units, leading to mistaken solutions in which unbalanced compressors and turbines are placed on the same shaft without either helper motors or generators. In addition, their oversimplified cost correlations (linear functions and fixed costs) are not able to realistically express process costs in real applications. The authors also consider unrealistic cost parameters that can eventually displace optimal solutions to those with less power consumption and high work exchange, as expressed by more equipment required in the network.

All above-mentioned approaches are based on the elementary assumption that the "thermal identity" (as hot or cold) of process streams is completely known before the task of network synthesis. In many industrial processes, nevertheless, the temperature of process streams is variable, making it difficult to clearly distinguish between the set of hot streams (streams requiring cooling) and cold streams (streams needing heating) for heat integration. Noticeably, sub-optimal solutions can be obtained when considering process synthesis and optimization. Kong et al. [22] have focused on solving this problem by proposing a MINLP-based formulation for process synthesis and heat integration, including streams whose classification as hot or cold streams cannot be defined a priori (hereafter, referred to as unclassified streams). The model proposed by the authors is an extension of the disjunctive model considering variable streams temperatures as developed by Navarro-Amorós et al. [23]. In the same way, 
Quirante et al. [24] have developed an alternative disjunctive model for the simultaneous heat integration of unclassified streams. Their model is based upon the modelling approach by Quirante et al. [25], in which «max» operators in the pinch location method (PLM) [26] are reformulated via disjunctions to reduce the number of equations and binary variables. We highlight that the distinction between hot and cold streams, and also among process and utilities streams, is even more challenging in simultaneous work and heat integration problems. This is mainly due to the potential changes in the stream thermal identity when undergoing pressure manipulation [3-5]. In this case, the consideration of unclassified process streams could be potentially advantageous to enhance WHENs energy efficiency.

To overcome shortcomings in previous research, we introduce a novel mathematical modelling approach for synthesizing cost-effective WHENs considering unclassified process streams. Our innovative systematic methodology combines mathematical programming techniques and the PLM, aiming at synergistically enhancing work and heat integration, while adjusting pressure and temperature levels of unclassified streams. To do so, we propose new disjunctive operators for the optimal selection of pressure changing equipment in WEN stages, as well as for the optimal streams identity classification. To the best of our knowledge, this is the first disjunctivebased model for the simultaneous optimization of WHENs synthesis to deal with unclassified streams.

Major novelties introduced by this work include the thermal identity classification of streams during the network optimization task, which allows taking advantage of energy requirements and operating conditions to further improve energy integration. Additionally, our method eliminates the need for assigning a precise route of pressure and temperature manipulation as previously proposed by Wechsung et al. 
[5]. Additionally, it does not require the streams classification either between HP and LP streams or even among no-pressure change and pressure change as proposed by Huang and Karimi [20]. Advantages of the new approach also include its ability to effectively handle unknown inlet and outlet temperatures (i.e., variable temperature conditions) to achieve any specific optimization goal. All these improvements together with a simplified mathematical formulation provide additional flexibility to our model, significantly enhancing energy-efficiency results and computational performance. Concerning the latter, our model can be easily solved to global optimality unlike preceding literature. Case studies based on LNG production and above-ambient processes are carried out to illustrate all the capabilities of the proposed new approach for the optimal WHEN synthesis.

This work is structured as follows. In Section 2, we provide a proper problem statement of the optimal WHEN synthesis considering unclassified process streams. In Section 3, we present the methodology and discuss the main challenges involved in WHENs optimization surmounted by the new modelling approach. The disjunctive mathematical model to solve the problem of optimal WHENs synthesis with unclassified streams is developed in Section 4. In Section 5, we demonstrate the improved cost-efficiency and computational performance of our model through several case studies. Finally, we summarize the main remarks and conclusions in Section 6.

\section{Problem statement}

The task of synthesizing work and heat transfer networks considering unclassified process streams can be formally stated as follows:

Given a set of high-pressure (HP) and low-pressure (LP) process streams that are unclassified in terms of their "thermal identity" as cold or hot streams; a set of 
pressure and temperature manipulation equipment; and, a set of utility streams and energy services; synthesize a cost-effective WHEN by performing the simultaneous work and heat integration at the minimal capital investment and operating expenses.

The set of unclassified streams (containing both HP and LP gaseous streams) is provided with a known supply state (defined by their inlet temperature, pressure and heat capacity flowrate) and a target condition (specified by their temperature and pressure manipulation requirements, in which the target pressure of some gaseous streams differ from their inlet state). It is noteworthy that our approach can also effectively handle unknown inlet and outlet streams temperatures to achieve specific optimization goals and improve solutions for the decision-making process. In this case, streams inlet and/or outlet temperatures are also treated as process decision variables. In addition, our model can be used for optimizing a wide range of processes that involves pressure and temperature changing of streams at both subambient and above-ambient conditions. The WHEN is comprised by several pieces of equipment for heat exchange (such as heat exchangers, coolers and heaters) and streams compression and expansion (which includes compressors, turbines and valves). Pressure manipulation equipment units are provided with their capital investment. Utility streams for cooling and heating as well as energy services (electric power) are also considered for the optimal WHEN synthesis with their corresponding operating expenses. Since the problem we are addressing is aimed at obtaining the most cost-effective WHEN design, we consider the minimization of the total annualized cost of the network as the objective function. Lastly, while our focus is the development of a systematic methodology for the WHEN synthesis rather than the rigorous design of single equipment units, we impose the following assumptions on the modelling approach:

(i). Steady state operation. 
(ii). All gaseous streams behave as an ideal gas.

(iii). All compressions and expansions (with exception for expansion through valves) are isentropic (adiabatic and reversible).

(iv). All expansions through valves are isenthalpic and irreversible with known constant Joule-Thomson coefficients.

(v). All turbines and compressors are centrifugal (built with carbon steel) and single-stage with known constant efficiencies.

(vi). All streams have known constant heat capacities and heat transfer coefficients.

(vii). Heat losses and pressure drop and in all thermal equipment are negligible.

(viii). Purchase costs of splitters and mixers are negligible.

\section{Methodology for the optimal WHEN synthesis}

The methodology is based on a multistage superstructure for the optimal WHEN synthesis that includes several stages of work and heat integration. The leading idea of the WHEN design is to connect the HEN with the WEN in such way that power and heat recovery processes-along with the resulting changes in pressure and temperature — can take advantage from each other to enhance overall energy integration. Thus, our WHEN superstructure consists of two different and interconnected multistage networks, wherein the heat integration exclusively occurs at the HEN while the work integration wholly takes place at the WEN. Note that all streams are reclassified before entering each superstructure stage to further improve heat and work integration. In this work, we consider that each pressure manipulation stage can be either composed by a stand-alone compressor, stand-alone turbine, valve or bypass (in case no equipment is 
required in the WEN stage). In addition, we keep the number of stages as lower as possible for reducing the size of the model. Fig. 1 depicts the superstructure for the stage $n$ of the WHEN with its main process decision variables.

Pressure manipulation plays a key role in above-ambient and subambient processes, since streams temperature (condensation and boiling temperatures) is highly dependent on pressure changes. Note that compression and expansion processes change both pressure and temperature of streams, when converting their enthalpy into work or vice-versa. As expected, properly manipulating both pressure and temperature is specially challenging during the WHEN design task. We emphasize that energy recovery from streams compression and expansion processes can be significantly enhanced by appropriately handling inlet temperatures in the corresponding pressure manipulation equipment. Hence, the expansion work (efficiency) is usually favoured by higher inlet temperatures, while the compression work (efficiency) is typically benefited by lower inlet temperatures.

To take full advantage of the above thermodynamic insights, we assume that streams needing expansion (commonly known as HP streams) must be treated as cold streams for heat integration. As a result, our model is mathematically formulated to ensure that if an unclassified process stream is classified as a cold stream in a given superstructure stage, then the only pressure manipulation allowed in such stage is via expansion. Similarly, streams requiring compression (or LP streams) must be considered as hot streams in HEN stages. Thus, if a stream is classified as a hot stream in a given stage, then it can only be compressed in such stage. Evidently, there is an optimal trade-off between the compression work consumed in the network and the amount of cooling utilities required to achieve lower temperatures. This is particularly 
important in subambient processes such as the energy-intensive LNG production, in which the prices of cooling utilities are extremely high.

One of the main advantages of this new approach is that the streams identity classification in each superstructure stage is carried out during the task of WHEN synthesis. The latter significantly improves system flexibility, allowing for the highest amount of energy to be recovered in the process. In this methodology, the streams undergoing pressure manipulation are not classified as HP or LP streams, which allows each of these streams to be either expanded or compressed depending on the process energy requirements. This is another major improvement, since it admits that the same process stream can undergo expansion in a given superstructure stage, and compression in the following WEN stage. Thus, the optimal route of pressure and temperature changes will ultimately be determined by the streams energy demand, the temperature range of available thermal utilities and associated operating expenses. Hence, this approach provides all flexibility required by the streams to follow the most appropriate pressure and temperature manipulation route for enhancing energy recovery.

In this type of problem, inlet temperatures in the WEN are decision variables that should meet outlet temperatures from the HEN (and vice-versa), which add further complexity to the conventional problem of optimal HEN design. When dealing with unclassified process streams, there is also an additional degree of freedom for each process stream in all WHEN stages. The raised number of new decision variables and constraints significantly increases the size of the model and computational efforts to reach the global optimum. To surpass these difficulties, along with keeping the superstructure as simple as possible, we combine mathematical programming techniques with the PLM [26] to reduce problem complexity and computing time consumption. The mathematical model is presented in the following sections. 


\section{Mathematical model}

The simultaneous modelling approach for the optimal WHENs synthesis considering unclassified process streams is developed through a GDP formulation, which is formally expressed as a MINLP optimization problem. For better understanding of the mathematical model, let us define the following index sets:

$$
\left.\begin{array}{l}
S T R=\{s / s=1,2, \ldots, S \text { is a process stream }\} \\
H O T_{s} \subseteq S T R=\left\{i_{s} / i_{s} \text { is a hot stream }\right\} \\
C O L D_{s} \subseteq S T R=\left\{j_{s} / j_{s} \text { is a cold stream }\right\} \\
U N C_{s} \subseteq S T R=\left\{k_{s} / k_{s} \text { is a unclassified stream }\right\}
\end{array}\right\} S T R=H O T_{s} \cup C O L D_{s} \cup U N C_{s}
$$

\subsection{Modelling of streams work exchange}

The work exchange model includes a disjunctive operator for multistage pressure manipulation, in addition to logical relationships and constraints on streams pressure and temperature. As discussed before, the pressure manipulation equipment should be chosen in accordance with the identity classification of the process streams. While the streams classification is enforced by a disjunctive operator in the heat integration model, we use the pressure manipulating operator and logical relationships to guarantee the optimal equipment selection in each work exchange stage.

Pressure manipulation operator. The following pressure manipulation operator is used for enforcing the selection of the appropriate pressure manipulation equipment to be assigned to the streams ( $s \in S T R$ ) in each stage $n \in N$ of the WHEN superstructure. 


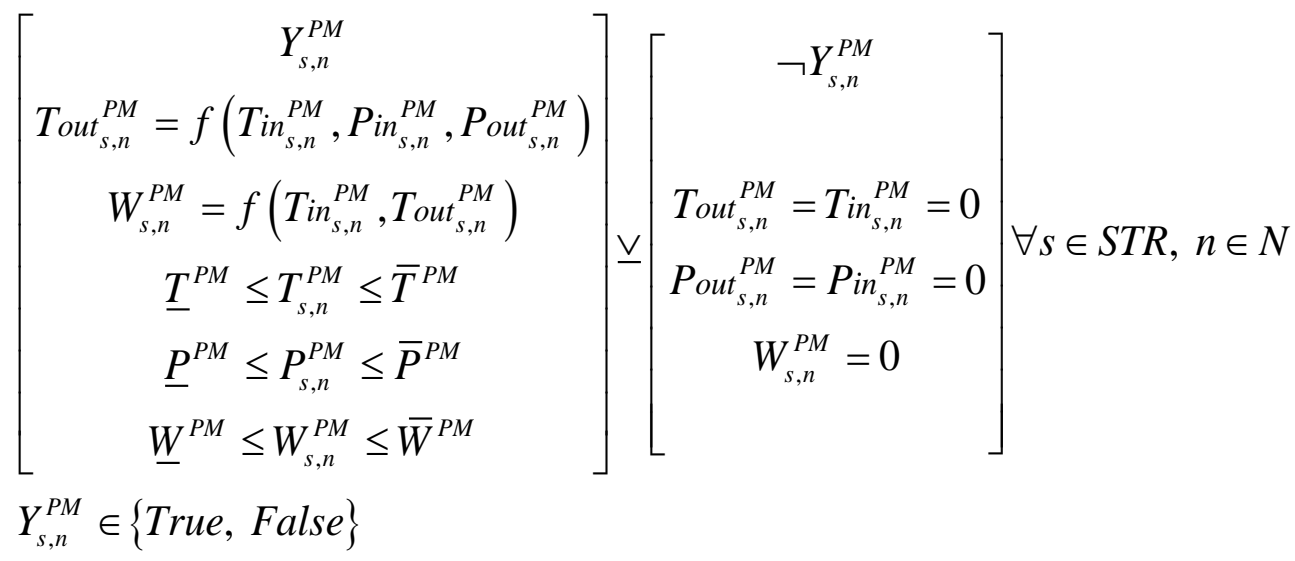

In above disjunction, $Y_{s, n}^{P M}$ is a Boolean variable used to express the discrete choices between the pressure manipulation equipment. Thus, $Y_{s, n}^{P M}$ takes the logic «True» value if a pressure manipulation equipment is used by the stream $s \in S T R$ in a stage $n \in N$. Otherwise, $Y_{s, n}^{P M}$ assume the logic «False» value. In Eq. (1), the superscript $P M$ stands for the set of pressure manipulation devices containing a compressor, turbine and valve. The previous disjunction can be rewritten in terms of binary variables using the following hull formulation (the interested reader is addressed to the Refs. [27] and [28] for more details about convex hull relaxation of disjunctive models):

$$
\begin{aligned}
& P_{I N_{s, n}}=\sum \operatorname{Pin}_{s, n}^{P M} ; \quad \operatorname{Pout}_{s, n}=\sum \operatorname{Pout}_{s, n}^{P M} \quad \forall s \in S T R, n \in N \\
& T_{I N} N_{s, n+1}=\sum \operatorname{Tin}_{s, n}^{P M} ; \quad \operatorname{ToUT}_{s, n}=\sum \text { Tout }_{s, n}^{P M} \quad \forall s \in S T R, n \in N \\
& 0 \leq \operatorname{Pin}_{s, n}^{P M} \leq \bar{P}_{i n}^{P M} \cdot y_{s, n}^{P M} \\
& \left.\begin{array}{l}
0 \leq \text { Pout }_{s, n}^{P M} \leq \bar{P}_{\text {out }}^{P M}{ }_{s, n}^{P M} \cdot y_{s, n}^{P M} \\
0 \leq \operatorname{Tin}_{s, n}^{P M} \leq \overline{T i n}_{s, n}^{P M} \cdot y_{s, n}^{P M}
\end{array}\right\} \forall s \in S T R, n \in N, P M \in\{C, T, V\} \\
& 0 \leq \text { Tout }_{s, n}^{P M} \leq \bar{T}_{\text {out }}^{P M} t_{s, n} \cdot y_{s, n}^{P M} \\
& 0 \leq W_{s, n}^{P M} \leq \bar{W}_{s, n}^{P M} \cdot y_{s, n}^{P M} \quad \forall s \in S T R, n \in N, P M \in\{C, T\} \\
& P_{s, n}^{P M} \geq 0, T_{s, n}^{P M} \geq 0, W_{s, n}^{P M} \geq 0, y_{s, n}^{P M} \in\{0,1\} \quad \forall s \in S T R, n \in N
\end{aligned}
$$


In which the variables $P_{I_{s, n}}$ and $P_{O U T_{s, n}}$ indicate the inlet and outlet pressures of the stream $s \in S T R$ in/from a given stage $n \in N$ of the superstructure. Note that these stage pressures should be equal to the respective inlet $\left(P_{i n_{s, n}^{P M}}^{P M}\right)$ and outlet $\left(P_{o u t}^{P M}\right)$ streams pressures in/from the pressure manipulation equipment (either compressor, turbine or valve) required in such stage. Similarly, $T_{I N_{s, n}}$ and $T_{o u T_{s, n}}$ are the inlet and outlet temperatures of the stream $s \in S T R$ in/from each stage $n \in N$, which should correspond to the inlet $\left(\operatorname{Tin}_{s, n}^{P M}\right)$ and outlet temperatures ( $\operatorname{Tout}_{s, n}^{P M}$ ) of the streams in/from the pressure manipulation equipment. These appropriate pressure and temperature assignments are assured by the inclusion of the first equalities shown in Eq. (2).

Needless to say, since only a single pressure manipulation equipment is allowed in each WEN stage, the summations in equality expressions in Eq. (2) are reduced to the inlet/outlet state variables corresponding to the selected device (or bypass). In other words, the stream $s \in S T R$ has only positive values for the inlet and outlet pressures and temperatures when allocated to the pressure manipulation equipment chosen in the considered stage. The same should occur with the consumed/performed work $W_{s, n}^{P M}$ by the compressor/turbine in the stage. If an equipment is not selected in the stage, the corresponding inlet and outlet pressures and temperatures of the stream, as well as the work should be zero. This behaviour is mathematically enforced by the inequalities constraints as shown in Eq. (2). Note that $y_{s, n}^{P M}$ is a binary variable that assumes the value 1 if a given pressure manipulation equipment is used in the stage. Otherwise, this binary variable takes the value 0 . In addition, the parameters $\left(\bar{P}_{i n_{s, n}^{P M}}^{P M}, \bar{P}_{o u t}{ }_{s, n}^{P M}, \bar{T}_{i n}^{P M}, \bar{W}_{s, n}^{P M}\right.$ ) are the valid upper bounds for the disaggregated pressure and temperature variables.

Pressure manipulation equipment such as compressors and turbines can be responsible for significant changes in temperature and pressure of gaseous streams. Let 
$\operatorname{Tin}_{s, n}^{C}$ be the inlet temperature of the stream $s \in S T R$ in the stage $n \in N$. So, the outlet temperature Tout $_{s, n}^{C}$ of the gaseous stream $s \in S T R$ from the adiabatic compressor (reversible process of compression of an ideal gas) in stage $n \in N$ is given as follows.

$$
\operatorname{Tout}_{s, n}^{C}=\operatorname{Tin}_{s, n}^{C} \cdot\left[1+\frac{1}{\eta_{s}} \cdot\left(\left(\text { Pout }_{s, n}^{C} / \operatorname{Pin}_{s, n}^{C}\right)^{\frac{\gamma_{s}-1}{\gamma_{s}}}-1\right)\right] \quad \forall s \in S T R, n \in N
$$

In which, $\eta_{s}$ represents the isentropic efficiency of the pressure manipulation device associated with the stream $s \in S T R$, and $\gamma_{s}$ indicates the corresponding heat capacity ratio $\left(C p_{s} / C v_{s}\right)$. The work consumed by the stand-alone compressor for the gaseous stream $s \in S T R$ in the stage $n \in N$ is given by the following equation.

$W_{s, n}^{C}=F_{s} \cdot\left(\right.$ Tout $\left._{s, n}^{C}-\operatorname{Tin}_{s, n}^{C}\right) \quad \forall s \in S T R, n \in N$

In the same way, the adiabatic and reversible process of expansion of an ideal gas is modelled as follows.

$$
\begin{aligned}
& \operatorname{Tout}_{s, n}^{T}=\operatorname{Tin}_{s, n}^{T} \cdot\left[1+\eta_{s} \cdot\left(\left(\operatorname{Pout}_{s, n}^{T} / \operatorname{Pin}_{s, n}^{T}\right)^{\frac{\gamma_{s}-1}{\gamma_{s}}}-1\right)\right] \quad \forall s \in S T R, n \in N \\
& W_{s, n}^{T}=F_{s} \cdot\left(\operatorname{Tin}_{s, n}^{T}-\operatorname{Tout}_{s, n}^{T}\right) \quad \forall s \in S T R, n \in N
\end{aligned}
$$

In which, $W_{s, n}^{T}$ indicates the work performed by a turbine that is used to drive the stream $s \in S T R$ in the stage $n \in N . F_{s}$ is the heat capacity flowrate (i.e., product of stream 
flowrate and heat capacity) of the stream $s \in S T R$. The isenthalpic expansion of the stream $s \in S T R$ passing through a valve in the stage $n \in N$ is given by,

$\operatorname{Tout}_{s, n}^{V}=\operatorname{Tin}_{s, n}^{V}+\mu_{s} \cdot\left(\right.$ Pout $\left._{s, n}^{V}-\operatorname{Pin}_{s, n}^{V}\right) \quad \forall s \in S T R, n \in N$

In which, $\mu_{s}$ represents the constant Joule-Thomson coefficient. In case no equipment is required in the stage $n \in N$, the outlet temperature and pressure of the stream $s \in S T R$ should be equal to its corresponding inlet state variables in such stage. To enforce the equality of inlet and outlet temperatures and pressures in the bypass, we use the following equations:

$$
\left.\begin{array}{l}
\operatorname{Tout}_{s, n}^{B}=\operatorname{Tin}_{s, n}^{B} \\
\operatorname{Pout}_{s, n}^{B}=\operatorname{Pin}_{s, n}^{B}
\end{array}\right\} \quad \forall s \in S T R, n \in N
$$

Logical relationships. We include some logical relationships in the mathematical model to ensure the optimal equipment selection for streams $s \in S T R$ in each stage $n \in N$ of the WHEN superstructure. Note that the logical relationships are introduced to reduce the search space by ensuring only feasible alternatives. Let $y_{s, n}^{P M}$ and $y_{s, n}^{B}$ be binary variables that respectively indicate the existence of a specific pressure manipulation device and bypass in the stage $n \in N$, in which, 
$y_{s, n}^{P M}= \begin{cases}1 & \text { if the stream } s \text { uses a pressure manipulation equipment in the stage } n \\ 0 & \text { otherwise }\end{cases}$ $y_{s, n}^{B}= \begin{cases}1 & \text { if the stream } s \text { passes through a bypass in the stage } n \\ 0 & \text { otherwise }\end{cases}$ $\forall s \in S T R, n \in N, P M \in\{C, T, V\}$

Clearly, if the stream $s \in S T R$ bypasses the stage $n \in N$ of the WHEN superstructure, then no equipment is used in such stage. Therefore, the selection in each stage $n \in N$ should be done between the compressor, turbine, valve and bypass. For simplifying the modelling formulation, compressors and turbines running on common shaft units (or single-shaft-turbine-compressor - SSTC units) are not allowed in this new approach. Note that our goal is much more focused on exploring synergies between work and heat integration processes for enhancing energy efficiency—by developing a systematic approach robust enough to easily ensure optimal solutions-rather than obtaining a complex network configuration. However, SSTC units can be effortlessly considered by including in the mathematical model formulation suitable design constraints and an energy balance in such shaft. This has been successfully addressed in our previous studies (see Refs. [3] and [19] for more specific details). We emphasize that only one alternative can be chosen at once. This excluding decision is enforced by the following relationship, which is written in terms of Boolean variables and its corresponding algebraic reformulation.

$$
\left(Y_{s, n}^{C} \underline{\vee} Y_{s, n}^{T} \underline{\vee} Y_{s, n}^{V} \underline{\vee} Y_{s, n}^{B}\right) \rightarrow y_{s, n}^{C}+y_{s, n}^{T}+y_{s, n}^{V}+y_{s, n}^{B}=1 \quad \forall s \in S T R, n \in N
$$

In light of previous discussion, we assume that if an unclassified stream $k_{s} \in U N C_{s}$ is classified as a hot stream in the stage $n \in N$ (the disjunctive classification 
operator is presented in next sections), then only a compressor or bypass can be allowed in such stage. The correct decision is ensured by Eq. (10).

$$
Y_{k_{s}, n}^{H O T} \Rightarrow\left(Y_{k_{s}, n}^{C} \underline{\vee} Y_{k_{s}, n}^{B}\right) \rightarrow 1-y_{k_{s}, n}^{H O T}+y_{k_{s}, n}^{C}+y_{k_{s}, n}^{B} \geq 1 \quad \forall k_{s} \in U N C_{s}, n \in N
$$

Alternatively, if an unclassified stream $k_{s} \in U N C_{s}$ is classified as a hot stream in the stage $n \in N$, then a decision should be made between a turbine, valve and bypass in such stage. The latter selection is enforced by the following logical relationship.

$$
Y_{k_{s}, n}^{C O L D} \Rightarrow\left(Y_{k_{s}, n}^{T} \underline{\vee} Y_{k_{s}, n}^{V} \underline{\vee} Y_{k_{s}, n}^{B}\right) \rightarrow 1-y_{k_{s}, n}^{C O L D}+y_{k_{s}, n}^{T}+y_{k_{s}, n}^{V}+y_{k_{s}, n}^{B} \geq 1 \quad \forall k_{s} \in U N C_{s}, n \in N
$$

Also, if the bypass occurs in the stage $n \in N$, then it should occur in all subsequent stages. This is performed by the following equation.

$$
1-y_{s, n}^{B}+y_{s, n+1}^{B} \geq 1 \quad \forall s \in S T R, n \in N
$$

Although the inclusion of above constraint is not strictly necessary, it ensures that the bypass can only occur in the stage $n \in N$ when temperature and pressure targets are already reached for the stream $s \in S T R$. It is important to remark that the last stage of the WHEN superstructure should be always composed by a heat integration stage followed by a WEN bypass to guarantee that the streams target temperatures can be effectively achieved in the system. 
Pressure and temperature assignments. Let the variables $P_{I N_{s}}{ }^{s}$ and $\operatorname{PoUt}_{s}^{s}$ represent, respectively, the inlet and outlet pressures of the stream $s \in S T R$ in/from the WHEN superstructure; and, $P_{I N_{s, n}}$ and $P_{o u T_{s, n}}$ the inlet and outlet intermediate pressures of the stream $s \in S T R$ in/from each stage $n \in N$ of pressure manipulation, correspondingly. The stream inlet pressure in the first pressure manipulation stage should be equal to the stream inlet pressure in the superstructure. Analogously, the streams outlet pressure from the last stage should correspond to the outlet pressure at the end of the superstructure. Thus, the streams inlet and outlet pressures in the superstructure are assigned as follows.

$$
\begin{array}{ll}
P_{I N} N_{s, n}=P_{I N} N_{s} & \forall s \in S T R, n=1 \\
P_{O U T}=P_{S O U T} S_{s} & \forall s \in S T R, n=N
\end{array}
$$

Likewise, temperatures assignment at inlet and outlet of the superstructure is given by Eq. (14).

$$
\begin{array}{ll}
T_{I N_{s, n}}=T_{I N} s & \forall s \in S T R, n=1 \\
\operatorname{ToUT}_{s, n}=\operatorname{ToUT}_{s} s^{s} & \forall s \in S T R, n=N
\end{array}
$$

Connection of pressure between stages. The streams pressures between consecutive stages in the superstructure are connected as follows.

$$
\operatorname{PoUT}_{s, n}=P_{I N}, \quad \forall s \in S T R, 1 \leq n<N
$$

\subsection{Streams classification operator}


Unclassified process streams should be identified as hot or cold streams in each stage $n \in N$ of the WHEN superstructure. Accordingly, the following disjunction and classification constraints are added to the mathematical model to enforce the optimal streams classification during the WHEN synthesis:

$$
\begin{aligned}
& {\left[\begin{array}{c}
Y_{k_{s}, n}^{\mathrm{HOT}} \\
T_{k_{s}, n}^{+} \geq 0 \\
T_{k_{s}, n}^{-}=0
\end{array}\right] \underline{\vee}\left[\begin{array}{c}
Y_{k_{s}, n}^{C O L D} \\
T_{k_{s}, n}^{-} \geq 0 \\
T_{k_{s}, n}^{+}=0
\end{array}\right] \quad \forall k_{s} \in U N C_{s}, n \in N} \\
& Y_{k_{s}, n}^{\mathrm{HOT}}, Y_{k_{s}, n}^{\mathrm{COLD}} \in\{\text { True, False }\}
\end{aligned}
$$

In which, $Y_{k_{s}, n}^{\mathrm{HOT}}$ and $Y_{k_{s}, n}^{C O L D}$ are Boolean variables that assume the logic «True» value if the unclassified stream $k_{s} \in U N C_{s}$ is classified in the stage $n \in N$ as a hot stream and cold stream, respectively. Otherwise, these Boolean variables take the «False» value. Here, we use classification constraints as proposed by Kong et al. [22]:

$$
\begin{aligned}
& T_{I N_{s, n}}-\operatorname{ToUT}_{s, n}=T_{s, n}^{+}-T_{s, n}^{-} \quad \forall s \in S T R, n \in N \\
& \begin{cases}T_{s, n}^{+}=0 & \forall s \in C O L D_{s}, n \in N \\
T_{s, n}^{-}=0 & \forall s \in H_{S}, n \in N\end{cases}
\end{aligned}
$$

Note that the variables $T_{s, n}^{+}$and $T_{s, n}^{-}$will be positive if the stream $s \in S T R$ is a hot stream and cold stream, correspondingly, in the stage $n \in N$ of the superstructure. The previous disjunction can be rewritten in terms of binary variables using the following hull formulation [29]: 


$$
\begin{aligned}
& \left.\begin{array}{l}
y_{k_{s}, n}^{H O T}+y_{k_{s}, n}^{C O L D}=1 \\
T_{k_{s}, n}^{+} \leq \bar{T}_{k_{s}, n}^{+} \cdot y_{k_{s}, n}^{H O T} \\
T_{k_{s}, n}^{-} \leq \bar{T}_{k_{s}, n}^{-} \cdot y_{k_{s}, n}^{C O L D}
\end{array}\right\} \forall k_{s} \in U N C_{s}, n \in N \\
& T_{k_{s}, n}^{+} \geq 0, T_{k_{s}, n}^{-} \geq 0, y_{k_{s}, n}^{H O T} \in\{0,1\}, y_{k_{s}, n}^{C O L D} \in\{0,1\} \quad \forall k_{s} \in U N C_{s}, n \in N
\end{aligned}
$$

In which, $T_{k_{s}, n}^{+}$and $T_{k_{s}, n}^{-}$indicate the temperature of the unclassified streams $k_{s} \in U N C_{s}$ classified as hot stream and cold stream, respectively, in the stage $n \in N$. In addition, $\bar{T}_{k_{s}, n}^{+}$and $\bar{T}_{k_{s}, n}^{-}$represent the corresponding upper bounds for the classified streams

temperatures. $y_{k_{s}, n}^{\mathrm{HOT}}$ and $y_{k_{s}, n}^{\mathrm{COLD}}$ are binary variables that assume the value 1 if the stream $k_{s} \in U N C_{s}$ is classified as hot stream and cold stream, respectively, in the stage $n \in N$ of the superstructure. Otherwise, these binary variables take the value 0 .

\subsection{Modelling of heat integration with unclassified streams}

We perform the streams heat integration by an improved disjunctive multistage formulation based on the well-known PLM [26] as proposed by Quirante et al. [24]. Thus, the heat integration model contains disjunctive operators for pinch location in each stage of the superstructure. In addition, our formulation takes advantage of reformulating «max» operators via disjunctions for reducing the relaxation gap-i.e., the difference between the MILP integer optimum and optimum value when binaries are relaxed as continuous variables-and improving numerical performance of the model. The detailed heat integration model is presented in the Appendix A.

\subsection{Objective function}


The resulting MINLP-based model is optimized through the minimization of the process total annualized cost (TAC). The objective function is composed by capital investment in equipment ( $C A P E X)$ and operational expenses (OPEX):

$\min \quad T A C=C A P E X+O P E X$

s.t. $\quad$ all equality and inequality constraints

In which,

$$
\begin{aligned}
& C A P E X=f a c \cdot\left(\frac{C E P C I^{2017}}{C E P C I^{2003}}\right) \cdot\left[\begin{array}{l}
F_{B M}{ }^{C} \cdot \sum_{s \in S T R} \sum_{n \in N} C_{P O}^{C}{ }_{s, n}^{C}+F_{B M}{ }^{T} \cdot \sum_{s \in S T R} \sum_{n \in N} C_{P O}^{T} O_{s, n}^{T} \\
+F_{B M}{ }^{V} \cdot \sum_{s \in S T R} \sum_{n \in N} C_{P O} O_{s, n}
\end{array}\right] \\
& O P E X=\left(C^{H O T} \cdot Q^{H O T}+C^{C O L D} \cdot Q^{C O L D}\right)+C^{E L E C} \cdot \sum_{s \in S T R} \sum_{n \in N} W_{s, n}^{C}
\end{aligned}
$$

In Eq. (19a), $F_{B M}$ is the factor of correction for the equipment basic cost related to construction materials and operating pressures range. In addition, $C_{P O}$ indicates the capital investment for each equipment (in kUS\$) for operation at conditions near the ambient pressure. In this work, we use the cost correlations given by Couper et al. [30] to estimate the capital investment of compressor and turbines, while the valves cost is obtained by the correlation of Turton et al. [31]. Note that the cost correlations for capital investment are corrected through the Chemical Engineering Plant Cost Index (CEPCI) for the interest year. The annualization factor for the capital cost fac is determined as proposed by Smith [32]. In Eq. (19b), $C^{\text {HOT }}, C^{\text {COLD }}$ and $C^{E L E C}$ are cost parameters for heating, cooling and electricity, respectively. Also, $Q^{H O T}$ and $Q^{\text {COLD }}$ are the amount of hot and cold utilities required in the process, correspondingly. $W_{s, n}^{C}$ refers 
to the work consumed by the compressors associated with the process streams ( $s \in S T R$ ) in each stage $(n \in N)$ of the WEN superstructure.

The resulting MINLP model was implemented in GAMS [33] (version 24.9.2) and solved to global optimality by using the deterministic global solver BARON (version 17.10.16) [34], with CPLEX 12.7 and SNOPT as sub-solvers. A computer with an Intel ${ }^{\circledR}$ Core $^{\mathrm{TM}}$ i5-3570 M 3.4 GHz processor and 8 GB RAM running Windows 10 was utilized for solving the case studies. The CPU times varied from 1-30 s to get global optimal solutions in the studied cases (depending on the number of process streams). We highlight that lower and upper bounds for both pressures and temperatures are critical to solve the problem within reduced computational times. The lower and upper bounds for the main decision variables are separately specified in each case study.

\section{Case studies}

Illustrative case studies extracted from the literature are used to verify the applicability of the new model for optimal WHENs synthesis, considering unclassified process streams at subambient and above-ambient conditions.

\subsection{Case study 1: Offshore LNG process}

The first example is based on the offshore LNG production using liquid carbon dioxide $\left(\mathrm{LCO}_{2}\right)$ and liquid inert nitrogen (LIN) as cold carriers, within the liquefied energy chain as proposed by Aspelund and Gundersen [6,7]. The liquefied energy chain is an energy and cost-effective transport chain for the stranded natural gas, which is employed for on-shore power production with carbon-capture and offshore enhanced oil recovery. The liquefied energy chain for natural gas is comprised by an integrated gas carrier to an offshore section with a receiving terminal (the reader is referred to Refs. $[6,7,35,36]$ for more information about the entire liquefied energy chain). In the 
offshore section, natural gas (NG) is liquefied to $\mathrm{LNG}$, while the $\mathrm{LCO}_{2}$ stream needs to be compressed and heated for using at the enhanced oil recovery plant. Thus, the NG is first compressed to achieve a pressure above the critical point. Afterwards, the highpressure NG is cooled by the $\mathrm{LCO}_{2}$ stream before the expansion until bubble point conditions (e.g., $-77^{\circ} \mathrm{C}$ and 50 bar). Then, it is sub-cooled by the high-pressure LIN stream and expanded to its transport or storage pressure. In the process, the LIN stream passes through two heat exchangers to liquefy the NG stream, and the heated nitrogen $\left(\mathrm{N}_{2}\right)$ is emitted to the atmosphere at ambient conditions. Also, the high-pressure carbon dioxide $\left(\mathrm{CO}_{2}\right)$ is transported to an offshore oilfield. In Wechsung et al. [5], the ExPAnD methodology is applied to improve the LNG production by extracting exergy from LIN and $\mathrm{LCO}_{2}$ cold carriers without additional streams utilities. Fig. 2 displays the process flow diagram for the offshore LNG production after applying the ExPAnD methodology as suggested by Wechsung et al. [5].

In this work, we use the new developed WHENs model to show how the energy efficiency of the LNG process can be further enhanced by the consideration of unclassified streams. For this purpose, we consider the heat and work integration of the $\mathrm{LCO}_{2}$, NG and LIN streams. The stream data are adapted from Wechsung et al. [5], which are based on production rates of $1.0 \mathrm{~kg} \mathrm{~s}^{-1}$ of LNG, $2.46 \mathrm{~kg} \mathrm{~s}^{-1}$ of $\mathrm{LCO}_{2}$ and 1.29 $\mathrm{kg} \mathrm{s}^{-1}$ of $\mathrm{N}_{2}$. To better model a real process, a linear piecewise approximation is used so that the NG stream is divided into three hot streams (H1-H3), and the $\mathrm{LCO}_{2}$ is separated into two distinct cold streams (C1-C2) with constant heat capacities and flowrates [5]. However, in contrast to previous works in literature [5,20], the LIN stream is decomposed into two cold streams (C3-C4) and one unclassified stream (UNC). The latter is considered to improve the system flexibility by allowing the unclassified LIN stream to be either compressed or expanded in each WHEN stage, 
depending on the process energy requirements and operating conditions. Observe that the LIN-UNC stream is reclassified as either a hot stream or cold stream before entering each superstructure stage. For this reason, streams identity along with all stage intermediate temperatures and pressures become unknown decision variables. In addition, the unclassified LIN-UNC stream corresponds to sub-streams C5-C7 and H4 in Fig.2. Hence, a total of eight different streams (i.e., three hot streams, four cold streams and one unclassified stream) and two utility streams are considered for the problem optimization, which is much more accurate and complex than only consider three process streams with averaged heat capacity flowrates as suggested by Huang and Karimi [20].

In this example, three stages are considered for heat and work integration in the WHEN. Moreover, the unclassified LIN-UNC stream should be expanded from 10 to 0.1 MPa. For modelling pressure manipulation equipment, we assume a non-ideal polytrophic exponent of 1.51 , as well as an isentropic efficiency factor of 0.7 and a Joule-Thomson coefficient of $1.961 \mathrm{~K} \mathrm{MPa}^{-1}$. In addition, the outlet temperature of the LIN-UNC stream is considered to be a decision variable of the process (i.e., no target temperature is set for the stream) to further improve flexibility and energy efficiency. All unknown streams temperatures (at the inlet and outlet of each heat integration and pressure manipulation stages) are restricted to a range of 80 to $380 \mathrm{~K}$. Hot and cold utilities are available at 383.15 and $93.15 \mathrm{~K}$, respectively. Also, a minimum temperature approach of $5 \mathrm{~K}$ is considered for heat integration. Finally, $10 \%$ of interest rate over a period of 10 years is defined for cost estimations. Table 1 shows the stream and cost data of the offshore LNG process considered for this example. 
Case study 1.A. Initially, the WHEN is designed by considering the outlet pressure of the stream LIN-UNC from the first stage of pressure manipulation limited to a range of 1-3.5 MPa, as proposed by Wechsung et al. [5]. We emphasize that, although the same optimal configuration and decision variables for this case study are obtained without such bounds for the referred outlet pressure, the latter restriction is only included in the model to slightly reduce the search space and computing time. We notice that the model takes about $30 \mathrm{~s}$ to solve the problem to global optimality without this restriction, against less than $10 \mathrm{~s}$ with it. In this case, the optimal WHEN configuration presents two pressure manipulation stages composed by stand-alone turbines with capacity of $125.81 \mathrm{~kW}$ and $78.21 \mathrm{~kW}$, respectively. Thus, a total work amount of $204.02 \mathrm{~kW}$ is generated by the system. The pressure manipulation of the unclassified stream occurs in the first and second stages of the WHEN superstructure, wherein the bypass is selected for the last stage. On the other hand, the unclassified LIN-UNC stream passes through one stage of heat integration. It should be pointed out that the unclassified LIN-UNC stream is classified as a cold stream in all heat and work integration stages of the WHEN. The temperature of the LIN-UNC stream reaches $180.53 \mathrm{~K}$ at the outlet of the WHEN superstructure. The hot utility load is equal to $21.08 \mathrm{~kW}$, while no cooling services are required in the process. These results highlight the effectiveness of our new approach, in which the heat requirements of the process are reduced by $88.7 \%$ while the work generated in the process is increased from $15.43 \mathrm{~kW}$ to $204.02 \mathrm{~kW}$, when compared to the results obtained by Wechsung et al. [5] after applying the ExPAnD methodology. The total annualized cost is equal to $22.06 \mathrm{kUS \$} \mathrm{year}{ }^{-1}$, of which 20.37 kUS\$ year $^{-1}$ are related to capital investment in turbines and $1.69 \mathrm{kUS \$}$ year $^{-1}$ to operational expenses (heating requirements). Fig. 3 depicts the optimal configuration and main decision variables obtained for the WHEN design in this case. 
Case study 1.B. For further enhancing work and heat integration in the LNG process, we also investigate the inclusion of the NG compression step into our optimal WHEN design, as proposed by Huang and Karimi [20]. However, differently from the latter authors, we model the compression process of the NG stream by considering it as an additional unclassified process stream. Thus, the streams LIN-UNC and NG-UNC are both treated as unclassified process streams. In this case, we use the operating conditions and stream data extracted from Huang and Karimi [20]. Hence, the NG-UNC stream should be liquefied from the initial condition of $288.15 \mathrm{~K}$ at $7 \mathrm{MPa}$ to the final state of $104.75 \mathrm{~K}$ at $10 \mathrm{MPa}$. The streams of $\mathrm{LCO}_{2}$ and LIN-UNC are cold carriers for the process, in which the pressure of the $\mathrm{LCO}_{2}$ stream is maintained unchanged (6 $\mathrm{MPa}$ ) while the LIN-UNC stream should be expanded from $10 \mathrm{MPa}(103.45 \mathrm{~K})$ to $0.1 \mathrm{MPa}$. We highlight that the outlet temperature of the $\mathrm{LCO}_{2}$ and LIN-UNC streams are both considered to be decision variables for the process (i.e., no target temperatures are set for these streams). The latter allows to increase system flexibility and reduce thermal utility requirements, which is extremely favourable for the offshore LNG process. Our approach also eliminates the need for setting either hot or cold utility loads to zero as considered by Huang and Karimi [20] that could eventually lead to sub-optimal solutions.

For providing a fair comparison between results, we perform the optimal WHEN synthesis twice. Firstly, we consider the optimal integration of NG-UNC stream compression and LIN-UNC stream expansion; and, afterwards, only the pressure manipulation of the LIN-UNC stream is carried out during the optimization task. In the first case, the optimal WHEN configuration is composed by two expansion stages for the LIN-UNC stream and one compression stage for the NG-UNC stream. Thus, a total 
work of $306.72 \mathrm{~kW}$ is generated in the system by two different stand-alone turbines, with capacities of $164.27 \mathrm{~kW}$ and $142.45 \mathrm{~kW}$ (which are placed in first and second stages of pressure manipulation, respectively). The work generated in the system is $\sim 8 \%$ higher than the work produced via optimal design without integrating the compression stage of the NG-UNC stream into the system, i.e., keeping the its pressure unchanged at $7 \mathrm{MPa}$ and the same conditions for the other streams. Though, a stand-alone compressor with capacity of $99.75 \mathrm{~kW}$ is now required in the process, which increases both capital

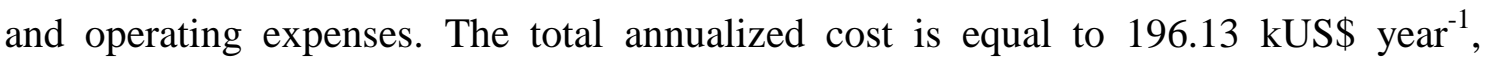
comprising $111.29 \mathrm{kUS}$ year $^{-1}$ associated with capital investment and $84.84 \mathrm{kUS} \$$ year $^{-}$ ${ }^{1}$ to operational expenses (electricity consumption). In contrast, if the pressure of the NG-UNC stream is not manipulated into the system, the optimal configuration presents a total annualized cost is equal to 26.82 kUS\$ year ${ }^{-1}$, which is entirely related to capital investment in turbines. Observe that, in this case, no hot or cold utilities or electricity services are required in the process.

Although higher costs are obtained for the optimal configuration with pressure manipulation of the NG-UNC stream, the integration of the compression step into the system also increases the heat integration of process streams. In this case, the stream NG-UNC passes through two stages of heat integration, while the LIN-UNC stream is subjected to three stages of heat integration. The outlet temperatures of the $\mathrm{LCO}_{2}$ and LIN-UNC streams reach $265.74 \mathrm{~K}$ and $221.12 \mathrm{~K}$, correspondingly. Our optimal WHEN design does not require cooling or heating services in the process (even without fixing these variables to zero as required in Huang and Karimi [20]), which also stresses the high effectiveness of our new approach. It should be pointed out that, due to fundamental thermodynamic inconsistencies found in the work of Huang and Karimi [20], as previously commented, it is not possible to compare our results with the results 
obtained by them. Fig. 4 displays the optimal configuration and main decision variables obtained for the WHEN design in this case.

The CPU time for the global deterministic optimization with the solver BARON has not exceeded $1 \mathrm{~s}$, when considering both LIN-UNC and NG-UNC streams as unclassified process streams. In this case, the mathematical model encompasses 988 continuous variables, 196 discrete variables, and 1,509 constraints with 3,398 Jacobian (non-zeros) elements, of which 108 are nonlinear. Although the combinatorial nature is more complex in this type of problem, its reformulation by using tighter relaxations and constraints, as well as lower number of nonlinear equations, allows obtaining much faster global optimal solutions (within less than $1 \mathrm{~s}$ ) than preceding works in literature $[4,5,20]$.

\subsection{Case study 2: Above-ambient process}

In this case study, we apply the proposed WHENs model to solve an illustrative example with process streams at above-ambient conditions. The data used for this case study are adapted from the work of Onishi et al. [4]. In this case, we perform the work and heat integration of two distinct process streams. In contrast to Onishi et al. [4], however, we consider both streams as unclassified process streams to increase system flexibility, allowing the streams can follow the most appropriate route of heat and pressure changes according to their energy requirements and process operating conditions. In the problem, one unclassified process stream (UNC-1) should be compressed from $0.1 \mathrm{MPa}(650 \mathrm{~K})$ to $0.5 \mathrm{MPa}$ at a target temperature condition of 370 $\mathrm{K}$, while a second stream (UNC-2) at $410 \mathrm{~K}$ should be expanded to a range of 0.5-0.1 $\mathrm{MPa}$. Note that the outlet temperature of the UNC-2 stream is considered as a process decision variable to further enhance system flexibility and energy efficiency. The 
superstructure outlet temperature for the UNC-2 is restricted to a range of $300-750 \mathrm{~K}$. Three stages of heat and work integration are considered in the superstructure, wherein UNC-1 and UNC-2 are classified between hot and cold streams. Therefore, streams identity and all stage intermediate temperatures and pressures are unknown decision variables. The unknown inlet streams temperatures at each heat integration stage are limited to a range of 400 to $550 \mathrm{~K}$, while the corresponding outlet ones are restricted to 300-750 K. Hot and cold utilities are available at $680 \mathrm{~K}$ and $300 \mathrm{~K}$, respectively. Also, a minimum temperature approach of $5 \mathrm{~K}$ is assumed for heat integration. Additionally, we use an ideal isentropic efficiency factor of 1 along with a Joule-Thomson coefficient of $1.961 \mathrm{~K} \mathrm{MPa}^{-1}$ and a polytrophic exponent of 1.352 for designing the pressure manipulation equipment. Lastly, $10 \%$ of interest rate over an amortization period of 10 years is defined for cost estimations. Table 2 presents the stream and cost data of the above-ambient process considered in this case study.

In this case, the optimal WHEN configuration is composed by two stand-alone compressors with a total capacity of $670.26 \mathrm{KW}$ for pressure manipulation of the unclassified UNC-1 stream. In addition, the network generates $416.38 \mathrm{~kW}$ by a standalone turbine placed at the first stage of pressure manipulation of the unclassified UNC2 stream. The UNC-1 stream passes through three different stages of heat integration, while the UNC-2 undergoes two distinct heat integration stages. It is noteworthy that the streams UNC-1 and UNC-2 are classified as hot and cold streams, respectively, for all stages of work and heat integration. Also, the temperature of the UNC-2 stream reaches $645 \mathrm{~K}$ at the outlet of the WHEN superstructure. The cold utility load is equal to $623.88 \mathrm{~kW}$, while no heating services are required in the process. The total annualized cost is equal to $965.71 \mathrm{kUS \$}$ year ${ }^{-1}$, of which $383.16 \mathrm{kUS \$} \mathrm{year} \mathrm{r}^{-1}$ are associated with capital investment in pressure manipulation equipment and $582.55 \mathrm{kUS \$}_{\text {year }}{ }^{-1}$ with 
operational expenses (electricity and cooling requirements). Observe that, because Onishi et al. [4] have simultaneously designed all heat exchange equipment in the HEN, it is not possible to compare our results with theirs. Fig. 5 depicts the optimal configuration and main decision variables obtained for the WHEN design in Case Study 2.

In this case, the mathematical model presents 1,056 continuous variables, 157 discrete variables, and 1,722 constraints with 3,650 Jacobian (non-zeros) elements, of which 144 are nonlinear. The CPU time for the global optimization with the solver BARON has not exceeded $1 \mathrm{~s}$. We stress that lower and upper bounds for the inlet and outlet temperatures of heat integration stages (from the pinch location method), as well as at the inlet and outlet of pressure manipulation stages should be carefully chosen for solving the problem within reduced computing times.

\section{Conclusions}

Work and heat integration is instrumental for achieving important energy and costs savings in both subambient and above-ambient processes. In this work, we introduce a novel modelling approach for the optimal WHENs synthesis considering unclassified streams. The proposed optimization model combines mathematical programming techniques and the PLM to synthesize a cost-effective WHEN, by adjusting pressure and temperature levels of unclassified streams. We propose a multistage superstructure that includes several stages of heat and work integration. In each superstructure stage, disjunctive operators are used to ensure the optimal selection of pressure manipulation equipment, as well as for the optimal streams identity classification.

The disjunctive operator for optimal streams classification during the WHEN design task is a major innovation introduced by this work, since it allows to take full 
advantage of process energy requirements and operating conditions to further enhance energy integration. In addition, our model eliminates the need for assigning a specific route of pressure and temperature manipulation and classifying streams between HP and LP streams. Our approach also avoids the selection of end-coolers and end-heaters as previously proposed by the literature, which provides significantly more flexibility to the system and robustness to the model. Furthermore, the new approach is able to effectively handle unknown inlet and outlet temperatures to reach any particular optimization goal. Together, these important improvements allow to greatly simplify the mathematical formulation, improving effectiveness expressed by the higher quality of solutions_-globally optimal solutions are indeed easily reached—and computational performance.

The mathematical model was implemented in GAMS and solved to global optimality by the minimization of the total annualized cost. The obtained results strongly highlight the effectiveness of our new modelling approach. In cryogenic LNG process, results from energy analysis reveal that streams classification during process optimization reduces the heat requirements of the process by $88.7 \%$ when compared to literature records. Regarding the increased computational performance, our model can be easily solved to global optimality unlike preceding works. In fact, the problem reformulation using tighter relaxations and constraints, allows reducing relaxation gap and numerical problems related to non-convex approximations, which results, in some cases, in global optimal solutions obtained within less than 1s. While our focus is to synergistically explore work and heat integration processes to improve WHENs costeffectiveness and computational performance, we keep the superstructure as simple as possible to reduce constraints and non-linearities. However, compressors and turbines could be designed to run into shared axes for obtaining potential savings in energy and 
process costs. Future research should also include the estimation of heat transfer areas and design of all heat exchanger equipment for a more detailed WHENs synthesis.

\section{Acknowledgements}

The authors are grateful for the financial support provided by the European Regional Development Fund (FEDER) through the Regional Operational Programme CENTRO 2020, within the scope of the project grant No. CENTRO-01-0145-FEDER-000006. The financial support provided by the Spanish «Ministerio de Economía, Industria y Competitividad», under project grant No. CTQ2016-77968-C3-2-P (AEI/FEDER, UE) is also gratefully acknowledged. 


\section{Nomenclature}

\section{Acronyms}

\begin{tabular}{|c|c|}
\hline CEPCI & Chemical Engineering Plant Cost Index \\
\hline ExPAnD & Extended Pinch Analysis and Design \\
\hline GAMS & General Algebraic Modeling System \\
\hline GDP & Generalized Disjunctive Programming \\
\hline HEN & Heat Exchanger Network \\
\hline HP & High-Pressure \\
\hline $\mathrm{LCO}_{2}$ & Liquid Carbon Dioxide \\
\hline LIN & Liquid Inert Nitrogen \\
\hline LNG & Liquefied Natural Gas \\
\hline LP & Low-Pressure \\
\hline MEN & Mass Exchanger Networks \\
\hline MILP & Mixed-Integer Linear Programming \\
\hline MINLP & Mixed-Integer Nonlinear Programming \\
\hline NG & Natural Gas \\
\hline PLM & Pinch Location Method \\
\hline SSTC & Single-Shaft-Turbine-Compressor \\
\hline WEN & Work Exchange Network \\
\hline WHEN & Work and Heat Exchange Network \\
\hline
\end{tabular}

\section{Greek letters}

$\begin{array}{ll}\gamma & \text { Heat capacity ratio } \\ \eta & \text { Isentropic efficiency } \\ \mu & \text { Joule-Thomson coefficient }\end{array}$




\section{Roman letters}

\begin{tabular}{|c|c|}
\hline CAPEX & Capital cost \\
\hline$C p$ & Heat capacity at constant pressure \\
\hline$C_{P O}$ & Unitary cost of equipment \\
\hline$C v$ & Heat capacity at constant volume \\
\hline$F$ & Heat capacity flowrate \\
\hline fac & Annualization factor for the capital cost \\
\hline$F_{B M}$ & Correction factor for capital cost \\
\hline$O P E X$ & Operational expenses \\
\hline$P_{I N}$ & Inlet streams pressure in stages of the superstructure \\
\hline $\operatorname{Pin}^{B}$ & Inlet streams pressure in a bypass \\
\hline $\operatorname{Pin}^{C}, \operatorname{Pin}^{T}, \operatorname{Pin}^{V}$ & $\begin{array}{l}\text { Inlet streams pressures in a compressor, turbine and valve, } \\
\text { respectively }\end{array}$ \\
\hline $\operatorname{Pin}^{P M}$ & Inlet streams pressure in a pressure manipulation equipment \\
\hline$P_{I N}^{S}$ & Inlet streams pressure from the superstructure \\
\hline Pout & Outlet streams pressure from stages of the superstructure \\
\hline Pout $^{B}$ & Outlet streams pressure in a bypass \\
\hline Pout $^{C}$, Pout $^{T}$, Pout $^{V}$ & $\begin{array}{l}\text { Outlet streams pressures in a compressor, turbine and valve, } \\
\text { respectively }\end{array}$ \\
\hline Pout $^{P M}$ & Outlet streams pressure from a pressure manipulation equipment \\
\hline$P_{\text {OUT }}^{S}$ & Outlet streams pressure from the superstructure \\
\hline$Q^{C O L D}$ & Heat removed by the cold utility \\
\hline$Q^{\text {НОT }}$ & Heat provided by the hot utility \\
\hline
\end{tabular}


Variable that takes positive values for hot streams

$T^{-}$

$T^{P i}$

TAC

$T_{I N}$

$\operatorname{Tin}^{B}$

$\operatorname{Tin}^{C}, \operatorname{Tin}^{T}, \operatorname{Tin}^{V}$

$\operatorname{Tin}^{P M}$

$T_{I N}^{S}$

$\operatorname{Tin}^{\text {Sh }}$

$\operatorname{TinC}^{\text {Sh }}$

$\operatorname{TinH}^{\text {Sh }}$

TINC

$T_{\text {INH }}$

TouT

Tout $^{B}$

Tout $^{C}$, Tout $^{T}$, Tout $^{V}$
Variable that takes positive values for cold streams

Pinch point temperature

Total annualized cost

Inlet streams temperature in stages of the superstructure

Inlet streams temperature in a bypass

Inlet streams temperatures in a compressor, turbine and valve, respectively

Inlet streams temperature in a pressure manipulation equipment

Inlet streams temperature from the superstructure

Shifted inlet temperature

Disaggregated variable for the shifted inlet temperatures of cold streams

Disaggregated variable for the shifted inlet temperatures of hot streams

Disaggregated variable for the actual inlet temperatures of cold streams

Disaggregated variable for the actual inlet temperatures of hot streams

Outlet streams temperature from stages of the superstructure

Outlet streams temperature in a bypass

Outlet streams temperatures in a compressor, turbine and valve, respectively 
Tout $^{\text {PM }}$

$T_{\text {OUT }}^{S}$

Tout $^{\text {Sh }}$

ToutC $^{\text {Sh }}$

ToutH

Toutc

TOUTH

$\Delta T_{\min }$

$W^{C}$

$W^{T}$

$W^{P M}$

$Y^{B}$

$Y^{C}, Y^{T}, Y^{V}$

$Y^{C O L D}$
Outlet streams temperature from a pressure manipulation equipment

Outlet streams temperature from the superstructure

Shifted outlet temperature

Disaggregated variable for the shifted outlet temperatures of cold streams

Disaggregated variable for the shifted outlet temperatures of hot streams

Disaggregated variable for the actual outlet temperatures of cold streams

Disaggregated variable for the actual outlet temperatures of hot streams

Minimum temperature approach

Consumed work by a compressor in the superstructure

Performed work by a turbine in the superstructure

Work of pressure manipulation equipment in the superstructure

Boolean variable that takes the logic «True» value if a given stream passes through a bypass in the superstructure

Boolean variables that take the logic «True» value if a given compressor, turbine and valve is respectively used by a stream in the superstructure

Boolean variables that take the logic «True» value if an unclassified stream is classified as a cold stream 
$Y^{H O T}$

$Y^{P M}$

$y^{B}$

$y^{C}, y^{T}, y^{V}$

$y^{C O L D}$

$y^{\mathrm{HOT}}$

$y^{P M}$

\section{Subscripts}

i

$j$

$k$

$n$

$p$

$S$
Boolean variables that take the logic «True» value if an unclassified stream is classified as a hot stream

Boolean variable that takes the logic «True» value if a given pressure manipulation equipment is used by a stream in the superstructure

Binary variable that assumes the value 1 if a given stream passes through a bypass in the superstructure

Binary variables that assume the value 1 if a given compressor, turbine and valve is respectively used by a stream in the superstructure

Binary variables that assume the value 1 if an unclassified stream is classified as a cold stream

Binary variables that assume the value 1 if an unclassified stream is classified as a hot stream

Binary variable that assumes the value 1 if a given pressure manipulation equipment is used by a stream in the superstructure

Hot process streams

Cold process streams

Unclassified process streams

Superstructure stages

Process streams that are pinch candidates

Process streams 


\section{Appendix A. Disjunctive model for HENs synthesis with unclassified streams}

The disjunctive modelling approach for the simultaneous multistage heat integration of unclassified process streams is developed as follows.

Definition of shifted temperatures. The shifted temperatures of hot streams $\left(i_{s} \in H O T_{s}\right)$ and cold streams $\left(j_{s} \in C O L D_{s}\right)$ in a stage $n \in N$ of the superstructure can be defined by Eq. (A.1).

$$
\begin{aligned}
& \left.\begin{array}{l}
\operatorname{Tin}_{i_{s}, n}^{S h}=\operatorname{TIN}_{i_{s}, n}-\frac{\Delta T_{\text {min }}}{2} \\
\operatorname{Tout~}_{i_{s}, n}^{\text {Sh }}=\operatorname{ToUT}_{i_{s}, n}-\frac{\Delta T_{\text {min }}}{2}
\end{array}\right\} \forall i_{s} \in H O T_{s}, n \in N \\
& \operatorname{Tin}_{j_{s}, n}^{S h}=T_{I N} j_{j_{s}, n}-\frac{\Delta T_{\min }}{2} \quad \forall j_{s} \in C O L D_{s}, n \in N \\
& \operatorname{Tout~}_{j_{s}, n}^{S h}=\operatorname{TouT}_{j_{s}, n}-\frac{\Delta T_{\min }}{2}
\end{aligned}
$$

In which, $T_{I N_{i_{s}, n}}, \operatorname{ToUt}_{i_{s}, n}, T_{I N} j_{j_{s}, n}$ and $\operatorname{ToUT}_{j_{s}, n}$ are the actual inlet and outlet temperatures of the hot and cold streams, respectively, in each stage of the superstructure. In addition, $\Delta T_{\min }$ indicates the minimum temperature approach considered for heat recovery. The appropriate temperature shift of an unclassified stream $k_{s} \in U N C_{s}$ in each stage $n \in N$ can be ensured by the following disjunction: 


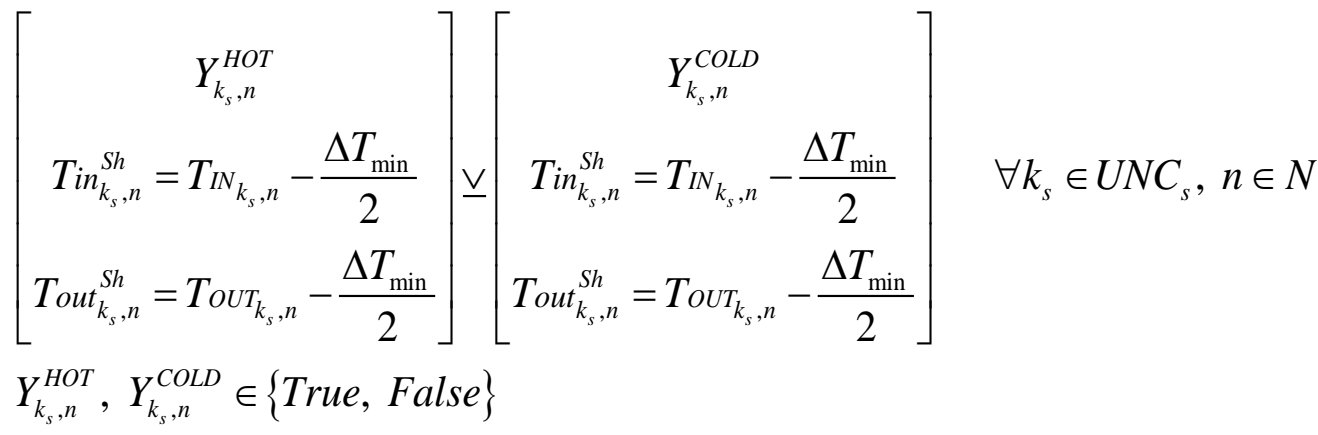

The disjunction in Eq. (A.2) can be rewritten in terms of the binary variables $y_{k_{s}, n}^{H O T}$ and $y_{k_{s}, n}^{C O L D}\left(\forall k_{s} \in U N C_{s}, n \in N\right)$ by means of the hull formulation as follows:

$$
\begin{aligned}
& y_{k_{s}, n}^{H O T}+y_{k_{s}, n}^{C O L D}=1 \\
& \operatorname{Tin}_{k_{s}, n}^{S h}=\operatorname{TinH}_{k_{s}, n}^{S h}+\operatorname{TinC}_{k_{s}, n}^{S h} \quad \text { Tout }_{k_{s}, n}^{S h}=\text { ToutH }_{k_{s}, n}^{S h}+\operatorname{ToutC}_{k_{s}, n}^{S h} \\
& \text { TIN }_{k_{s}, n}=T_{\text {INH }_{k_{s}, n}}+\text { TINC }_{k_{s}, n} \quad \text { ToUT }_{k_{s}, n}=\text { ToUTH }_{k_{s}, n}+\text { ToUTC }_{k_{s}, n} \\
& \operatorname{TinH}_{k_{s}, n}^{S h}=T_{I N H_{k_{s}, n}}-\frac{\Delta T_{\min }}{2} \cdot y_{k_{s}, n}^{H O T} \quad \operatorname{ToutH}_{k_{s}, n}^{\text {Sh }}=\text { ToUTH }_{k_{s}, n}-\frac{\Delta T_{\min }}{2} \cdot y_{k_{s}, n}^{H O T} \\
& \left.\operatorname{TinC}_{k_{s}, n}^{S h}=T_{I N C_{k_{s}, n}}-\frac{\Delta T_{\min }}{2} \cdot y_{k_{s}, n}^{\text {COLD }} \quad \operatorname{ToutC}_{k_{s}, n}^{S h}=\operatorname{ToUTC}_{k_{s}, n}-\frac{\Delta T_{\min }}{2} \cdot y_{k_{s}, n}^{\text {COLD }}\right\} \forall k_{s} \in U N C_{s}, n \in N \\
& \operatorname{TinH}_{k_{s}, n}^{\text {Sh }} \leq \overline{T i n H}_{k_{s}, n}^{S h} \cdot y_{k_{s}, n}^{\text {HOT }} \quad \operatorname{ToutH}_{k_{s}, n}^{\text {Sh }} \leq \bar{T}_{\text {out }}{ }_{k_{s}, n}^{\text {Sh }} \cdot y_{k_{s}, n}^{\text {HOT }} \\
& \operatorname{TinC}_{k_{s}, n}^{S h} \leq \bar{T}_{\text {inC }} C_{k_{s}, n}^{S h} \cdot y_{k_{s}, n}^{\text {COLD }} \quad \operatorname{ToutC}_{k_{s}, n}^{\text {Sh }} \leq \bar{T}_{\text {out }} \text { Ch }_{k_{s}, n}^{S h} \cdot y_{k_{s}, n}^{\text {COLD }} \\
& T_{\text {INH }_{k_{s}, n}} \leq \bar{T}_{\text {INH }_{k_{s}, n}} \cdot y_{k_{s}, n}^{\text {HOT }} \quad \text { TOUTH }_{k_{s}, n} \leq \bar{T}_{\text {OUTH }_{k_{s}, n}} \cdot y_{k_{s}, n}^{\text {HOT }} \\
& \operatorname{TINC}_{k_{s}, n} \leq \bar{T}_{I^{\prime N C} C_{k_{s}}, n} \cdot y_{k_{s}, n}^{\text {COLD }} \quad \text { ToUTC }_{k_{s}, n} \leq \bar{T}_{\text {OUTC }_{k_{s}}, n} \cdot y_{k_{s}, n}^{\text {COLD }} \\
& y_{k_{s}, n}^{H O T} \in\{0,1\}, y_{k_{s}, n}^{C O L D} \in\{0,1\} \quad \forall k_{s} \in U N C_{s}, n \in N
\end{aligned}
$$

In previous reformulation, $\operatorname{TinH}_{k_{s}, n}^{S h}, \operatorname{TinC}_{k_{s}, n}^{S h}, \operatorname{ToutH}_{k_{s}, n}^{S h}$, ToutC $C_{k_{s}, n}^{S h}$ indicate the disaggregated variables for the shifted inlet and outlet temperatures of the stream $k_{s} \in U N C_{s}$ in a stage $n \in N$. Likewise, $T_{I N H_{k_{s}}, n}, T_{I N C_{k_{s}, n}}$, ToUTH $_{k_{s}, n}$, ToUTC $_{k_{s}, n}$ refer to the disaggregated variables for inlet and outlet actual temperatures. 
Pinch temperature assignment. The inlet temperatures of all streams are potential pinch candidates, when considering constant heat flows. For the sake of clarity, we introduce the new variable $T_{s, n}^{P i}$ as stated by Eq. (A.4).

$T_{s, n}^{P i}=\operatorname{Tin}_{k_{s}, n}^{S h} \quad \forall s \in S T R, n \in N$

Disjunctive formulation for the «max» operator. The PLM as proposed by Duran and Grossmann [26] stablishes that, given a minimum temperature approach $\Delta T_{\min }$, the total amount of hot and cold utilities should be provided by the pinch candidate with the highest heating and cooling demands (corresponding to their energy contents above and below the pinch), respectively. Mathematically, this result can be expressed as follows.

$\left.\begin{array}{l}Q^{\text {HOT }}=\max \left(Q_{p_{s}}^{\text {HOT }}\right) \\ Q^{C O L D}=\max \left(Q_{p_{s}}^{C O L D}\right)\end{array}\right\} \forall p_{s} \in S T R$

In which, $Q^{\text {HOT }}$ and $Q^{\text {COLD }}$ are the heating and cooling utilities for an assumed $\Delta T_{\min }$, correspondingly. $Q_{p}^{H O T}$ and $Q_{p}^{C O L D}$ respectively refer to the heating and cooling demands for each pinch candidate $p_{s} \in S T R$. Observe that the index $p_{s} \in S T R$ is used to represent the set of potential pinch candidates that can be either hot or cold streams. Duran and Grossmann [26] have also shown that the heat contents below the pinch for each pinch candidate can be calculated by the following equation: 


$$
Q_{p_{s}}^{C O L D}=\left(\begin{array}{c}
\sum_{j_{s} \in C O L D} F_{j_{s}} \cdot\left[\max \left(0, T_{p_{s}}^{P i}-\text { Tout }_{j_{s}}^{S h}\right)-\max \left(0, T_{p_{s}}^{P i}-T_{i n}^{S h} j_{j_{s}}^{S h}\right)\right] \\
-\sum_{i_{s} \in H O T} F_{i_{s}} \cdot\left[\max \left(0, T_{p_{s}}^{P i}-T_{i n}^{S h} i_{i_{s}}^{S h}\right)-\max \left(0, T_{p_{s}}^{P i}-T_{\text {out }}^{S h}\right)\right]
\end{array}\right) \quad \forall p_{s} \in S T R
$$

Here, we extend Eq. (A.6) to account for the estimation of the cooling demands of the pinch candidates in the different stages $n \in N$ of the superstructure, and also to include unclassified process streams:

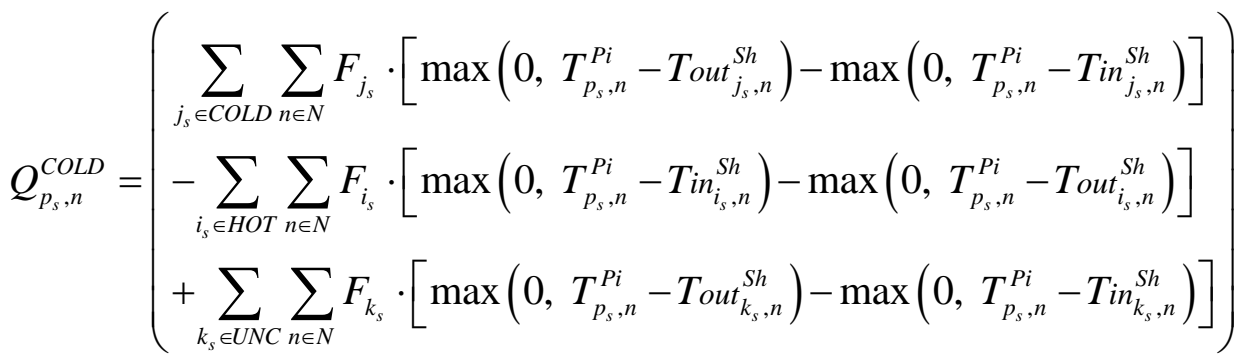

$$
\begin{aligned}
& \forall p_{s} \in S T R
\end{aligned}
$$

Note that the previous equation can be rewritten in a simpler form by using the index $s \in S T R$, which gathers hot, cold and unclassified process streams:

$$
Q_{p_{s}, n}^{C O L D}=\sum_{s \in S T R} \sum_{n \in N} F_{s} \cdot\left[\max \left(0, T_{p_{s}, n}^{P i}-T_{o u t}^{S h, n}\right)-\max \left(0, T_{p_{s}, n}^{P i}-T_{i n}^{S h} n_{s, n}^{S h}\right)\right] \quad \forall p_{s} \in S T R
$$

Since the previous «max» operator is non-differentiable at $T=T_{p_{s}}^{P i}$, it cannot be straightforwardly implemented in the optimization model. To overcome this limitation, we propose a disjunctive formulation based on the alternative model developed by Quirante et al. [25]. Apart from the ability to directly deal with the «max» operator, the 
model of Quirante et al. [25] has also advantages related to the reduced number of required equations and binary variables, as well as better relaxation gap and tighter bounds. The reader is addressed to the Ref. [25] for the complete hull reformulation of the «max» operator $\phi=\max \left(0, \mathbf{c}^{T} \mathbf{x}\right), \underline{\mathbf{x}} \leq \mathbf{x} \leq \overline{\mathbf{x}}$, expressed by disjunctions, including the tight upper and lower bounds for the auxiliary variables $\phi$ and $S$. Therefore, the «max» operator needed to calculate the minimum utilities can be reformulated as an optimization model by using the following disjunctions:

$$
\begin{aligned}
& \phi_{s, n, p, m}^{i n}=\operatorname{Tin}_{s, n}^{S h}-T_{p, m}^{P i}+S_{s, n, p, m}^{i n} \\
& \left.\left[\begin{array}{c}
Y_{s, n, p, m}^{i n} \\
S_{s, n, p, m}^{i n}=0
\end{array}\right] \underline{\vee}\left[\begin{array}{c}
\neg Y_{s, n, p, m}^{i n} \\
\phi_{s, n, p, m}^{i n}=0
\end{array}\right]\right\} \forall s, p \in S T R, n, m \in N \\
& \phi_{s, n, p, m}^{\text {out }}=\text { Tout }_{s, n}^{S h}-T_{p, m}^{P i}+S_{s, n, p, m}^{\text {out }} \\
& \left.\left[\begin{array}{c}
Y_{s, n, p, m}^{\text {out }} \\
S_{s, n, p, m}^{\text {out }}=0
\end{array}\right] \underline{\vee}\left[\begin{array}{c}
\neg Y_{s, n, p, m}^{\text {out }} \\
\phi_{s, n, p, m}^{\text {out }}=0
\end{array}\right]\right\} \forall s, p \in S T R, n, m \in N \\
& Y_{s, n, p, m}^{\text {in }}, Y_{s, n, p, m}^{\text {out }} \in\{\text { True, False }\}
\end{aligned}
$$

In Eq. (A.9), if the Boolean variables $Y_{s, n, p, m}^{\text {in }}$ and $Y_{s, n, p, m}^{\text {out }}$ take the logic «True» value, the variable $\phi_{s, n, p, m}^{\text {in }}$ is positive (or, the slack variable $S_{s, n, p, m}^{\text {in }}$ is equal to zero). Otherwise, $\phi_{s, n, p, m}^{\text {in }}$ is equal to zero. The following hull formulation can be used to rewrite the preceding equation in terms of the binary variables $y_{s, n, p, m}^{\text {in }}$ and $y_{s, n, p, m}^{\text {out }}$ : 


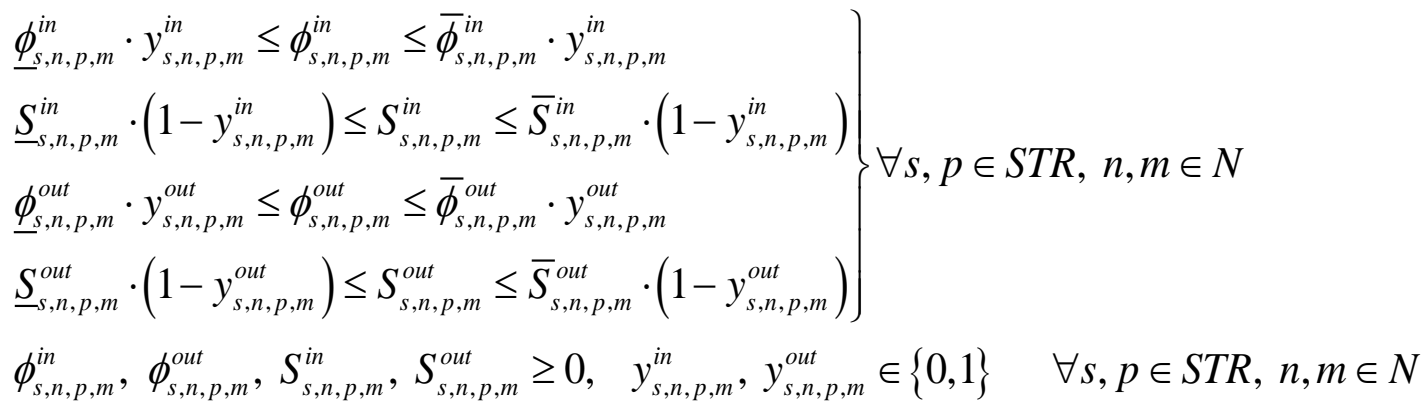

In which the symbols $\underline{\phi}$ and $\underline{S}$ indicate the lower bounds for the variables $\phi$ and $S$, while the symbols $\bar{\phi}$ and $\bar{S}$ refer to the corresponding upper bounds for the same variables.

Global heat balance. The global heat balance of the process is finally given by Eq. (A.11).

$Q^{C O L D}=Q^{H O T}+\sum_{s \in S T R} \sum_{n \in N} F_{s} \cdot\left[T_{s, n}^{+}-T_{s, n}^{-}\right]$

In which, the heating utility demand is defined by the following constraint:

$$
Q^{H O T} \geq \sum_{s \in S T R} \sum_{n \in N} F_{s} \cdot\left[\phi_{s, n, p, m}^{\text {out }}-\phi_{s, n, p, m}^{\text {in }}\right] \quad \forall p \in S T R, m \in N
$$




\section{References}

[1] Goh WS, Wan YK, Tay CK, Ng RTL, Ng DKS. Automated targeting model for synthesis of heat exchanger network with utility systems. Appl Energy 2016;162:1272-81. doi:10.1016/j.apenergy.2015.04.113.

[2] Onishi VC, Ravagnani MASS, Jiménez L, Caballero JA. Multi-objective synthesis of work and heat exchange networks: Optimal balance between economic and environmental performance. Energy Convers Manag 2017;140:192-202. doi:10.1016/j.enconman.2017.02.074.

[3] Onishi VC, Ravagnani MASS, Caballero JA. Retrofit of heat exchanger networks with pressure recovery of process streams at sub-ambient conditions. Energy Convers Manag 2015;94:377-93. doi:10.1016/j.enconman.2015.02.002.

[4] Onishi VC, Ravagnani MASS, Caballero JA. Simultaneous synthesis of heat exchanger networks with pressure recovery: Optimal integration between heat and work. AIChE J 2014;60:893-908. doi:10.1002/aic.14314.

[5] Wechsung A, Aspelund A, Gundersen T, Barton PI. Synthesis of heat exchanger networks at subambient conditions with compression and expansion of process streams. AIChE J 2011;57:2090-108. doi:10.1002/aic.12412.

[6] Aspelund A, Gundersen T. A liquefied energy chain for transport and utilization of natural gas for power production with $\mathrm{CO}_{2}$ capture and storage - Part 1. Appl Energy 2009;86:781-92. doi:10.1016/j.apenergy.2008.10.010.

[7] Aspelund A, Gundersen T. A liquefied energy chain for transport and utilization of natural gas for power production with $\mathrm{CO}_{2}$ capture and storage - Part 2: The offshore and the onshore processes. Appl Energy 2009;86:793-804. doi:10.1016/j.apenergy.2008.10.022.

[8] Huang YL, Fan LT. Analysis of a Work Exchanger Network. Ind Eng Chem Res 
1996;35:3528-38. doi:10.1021/ie9507383.

[9] Holiastos K, Manousiouthakis V. Minimum hot/cold/electric utility cost for heat exchange networks. Comput Chem Eng 2002;26:3-16. doi:10.1016/S00981354(01)00726-8.

[10] Linnhoff B, Townsend DW, Boland D, Hewitt GF, Thomas BEA, Guy AR, et al. User Guide on Process Integration for the Efficient Use of Energy. Pergamon Press Oxford 1982.

[11] Townsend DW, Linnhoff B. Heat and power networks in process design. Part II: Design procedure for equipment selection and process matching. AIChE J 1983;29:748-71. doi:10.1002/aic.690290509.

[12] Townsend DW, Linnhoff B. Heat and power networks in process design. Part I: Criteria for placement of heat engines and heat pumps in process networks. AIChE J 1983;29:742-8. doi:10.1002/aic.690290508.

[13] Aspelund A, Berstad DO, Gundersen T. An Extended Pinch Analysis and Design procedure utilizing pressure based exergy for subambient cooling. Appl Therm Eng 2007;27:2633-49. doi:10.1016/j.applthermaleng.2007.04.017.

[14] Linnhoff B, Vredeveld DR. Pinch technology has come of age. Chem Eng Prog 1984;80:33-40.

[15] Fu C, Gundersen T. Integrating expanders into heat exchanger networks above ambient temperature. AIChE J 2015;61:3404-22. doi:10.1002/aic.14968.

[16] Fu C, Gundersen T. Correct integration of compressors and expanders in above ambient heat exchanger networks. Energy 2016;116:1282-93. doi:10.1016/j.energy.2016.05.092.

[17] Fu C, Gundersen T. Heat and work integration: Fundamental insights and applications to carbon dioxide capture processes. Energy Convers Manag 
2016;121:36-48. doi:10.1016/j.enconman.2016.04.108.

[18] Razib MS, Hasan MMF, Karimi IA. Preliminary synthesis of work exchange networks. Comput Chem Eng 2012;37:262-77.

[19] Onishi VC, Ravagnani MASS, Caballero JA. Simultaneous synthesis of work exchange networks with heat integration. Chem Eng Sci 2014;112:87-107.

[20] Huang K, Karimi IA. Work-heat exchanger network synthesis (WHENS). Energy 2016;113:1006-17. doi:10.1016/j.energy.2016.07.124.

[21] Onishi VC, Ravagnani MASS, Caballero JA. MINLP Model for the Synthesis of Heat Exchanger Networks with Handling Pressure of Process Streams. Comput. Aided Chem. Eng., vol. 33, Elsevier; 2014, p. 163-8. doi:10.1016/B978-0-44463456-6.50028-4.

[22] Kong L, Avadiappan V, Huang K, Maravelias CT. Simultaneous chemical process synthesis and heat integration with unclassified hot/cold process streams. Comput Chem Eng 2017;101:210-25. doi:10.1016/j.compchemeng.2017.02.024.

[23] Navarro-Amorós MA, Caballero JA, Ruiz-Femenia R, Grossmann IE. An alternative disjunctive optimization model for heat integration with variable temperatures. Comput Chem Eng 2013;56:12-26.

[24] Quirante N, Grossmann IE, Caballero JA. Disjunctive model for the simultaneous optimization and heat integration with unclassified streams and area estimation. Comput Chem Eng 2018;108:217-31. doi:10.1016/j.compchemeng.2017.09.013.

[25] Quirante N, Caballero JA, Grossmann IE. A novel disjunctive model for the simultaneous optimization and heat integration. Comput Chem Eng 2017;96:149-68. doi:10.1016/j.compchemeng.2016.10.002.

[26] Duran MA, Grossmann IE. Simultaneous optimization and heat integration of chemical processes. AIChE J 1986;32:123-138. 
[27] Lee S, Grossmann IE. New algorithms for nonlinear generalized disjunctive programming. Comput Chem Eng 2000;24:2125-41.

[28] Vecchietti A, Lee S, Grossmann IE. Modeling of discrete/continuous optimization problems: characterization and formulation of disjunctions and their relaxations. Comput Chem Eng 2003;27:433-48. doi:10.1016/S00981354(02)00220-X.

[29] Trespalacios F, Grossmann IE. Review of Mixed-Integer Nonlinear and Generalized Disjunctive Programming Methods. Chemie Ing Tech 2014;86:9911012. doi:10.1002/cite.201400037.

[30] Couper JR, Penney WC, Fair JR, Walas SM. Chemical process equipment, selection and design. Second Edi. USA: Elsevier; 2010.

[31] Turton R, Bailie RC, Whiting WB, Shaeiwitz JA, Bhattacharyya D. Analysis, Synthesis, and Design of Chemical Processes. Fourth. Prentice Hall; 2012.

[32] Smith RM. Chemical Process Design and Integration. England: John Wiley \& Sons Ltd; 2005.

[33] Richard E. Rosenthal. GAMS — A User's Guide. Washington, DC: GAMS Development Corporation; 2016.

[34] Tawarmalani M, Sahinidis N V. A polyhedral branch-and-cut approach to global optimization. Math Program 2005;103:225-49. doi:10.1007/s10107-005-0581-8.

[35] Aspelund A, Tveit SP, Gundersen T. A liquefied energy chain for transport and utilization of natural gas for power production with $\mathrm{CO}_{2}$ capture and storage Part 3: The combined carrier and onshore storage. Appl Energy 2009;86:805-14.

[36] Aspelund A, Gundersen T. A liquefied energy chain for transport and utilization of natural gas for power production with $\mathrm{CO}_{2}$ capture and storage - Part 4: Sensitivity analysis of transport pressures and benchmarking with conventional 
technology for gas transport. Appl Energy 2009;86:815-25. 


\section{List of Figure Captions}

Fig. 1. Superstructure proposed for the stage $n$ of the WHEN along with the main process decision variables.

Fig. 2. Process flow diagram for the offshore LNG process after the application of ExPAnD methodology.

Fig. 3. Optimal configuration and main decision variables obtained for the WHEN design in Case study 1, considering the LIN stream as an unclassified process stream.

Fig. 4. Optimal configuration and main decision variables obtained for the WHEN design in Case study 1, considering both the LIN stream and the NG stream as unclassified process streams.

Fig. 5. Optimal configuration and main decision variables obtained for the WHEN design in Case study 2. 


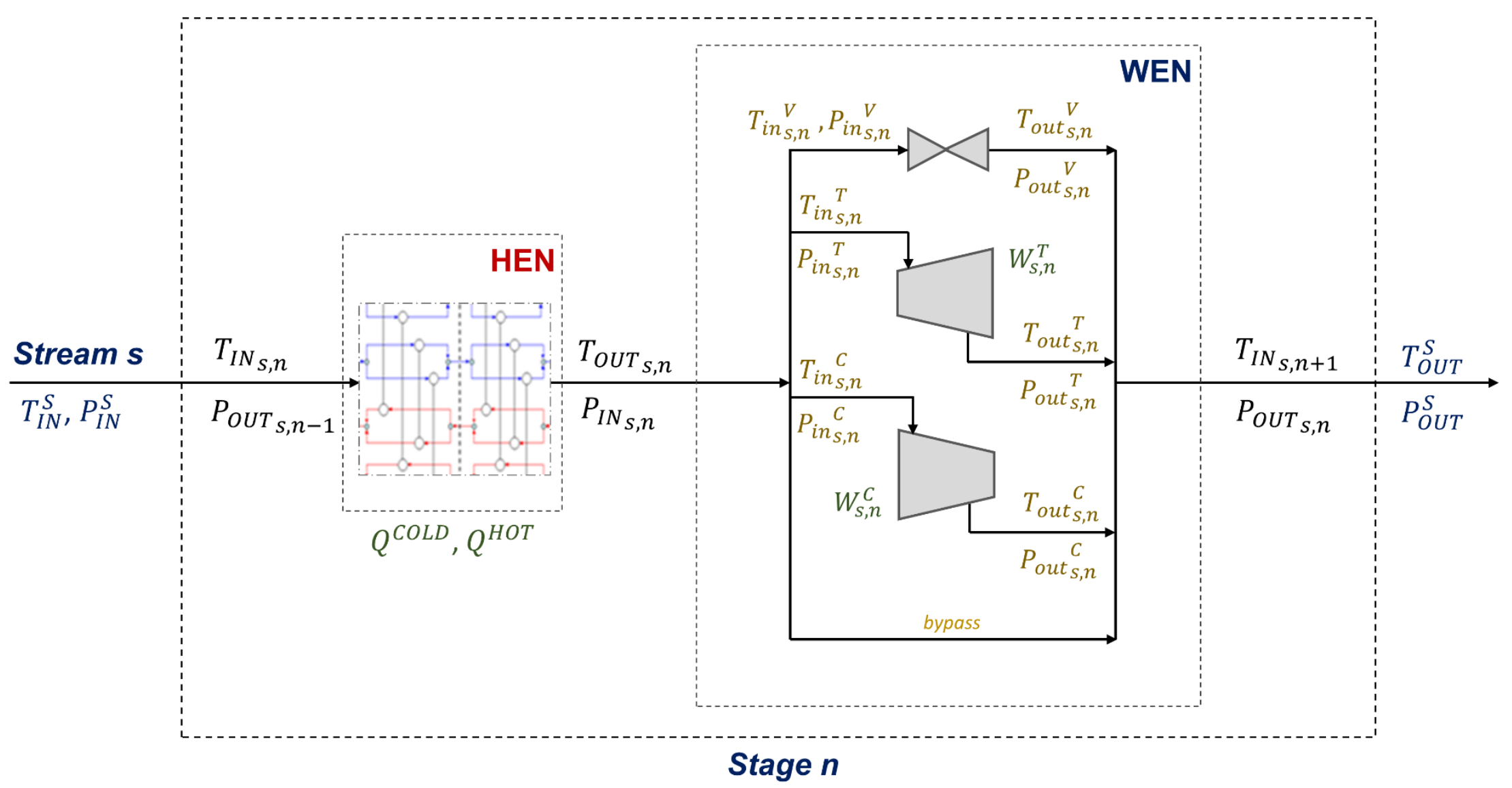

Fig. 1. Superstructure proposed for the stage $n$ of the WHEN along with the main process decision variables. 


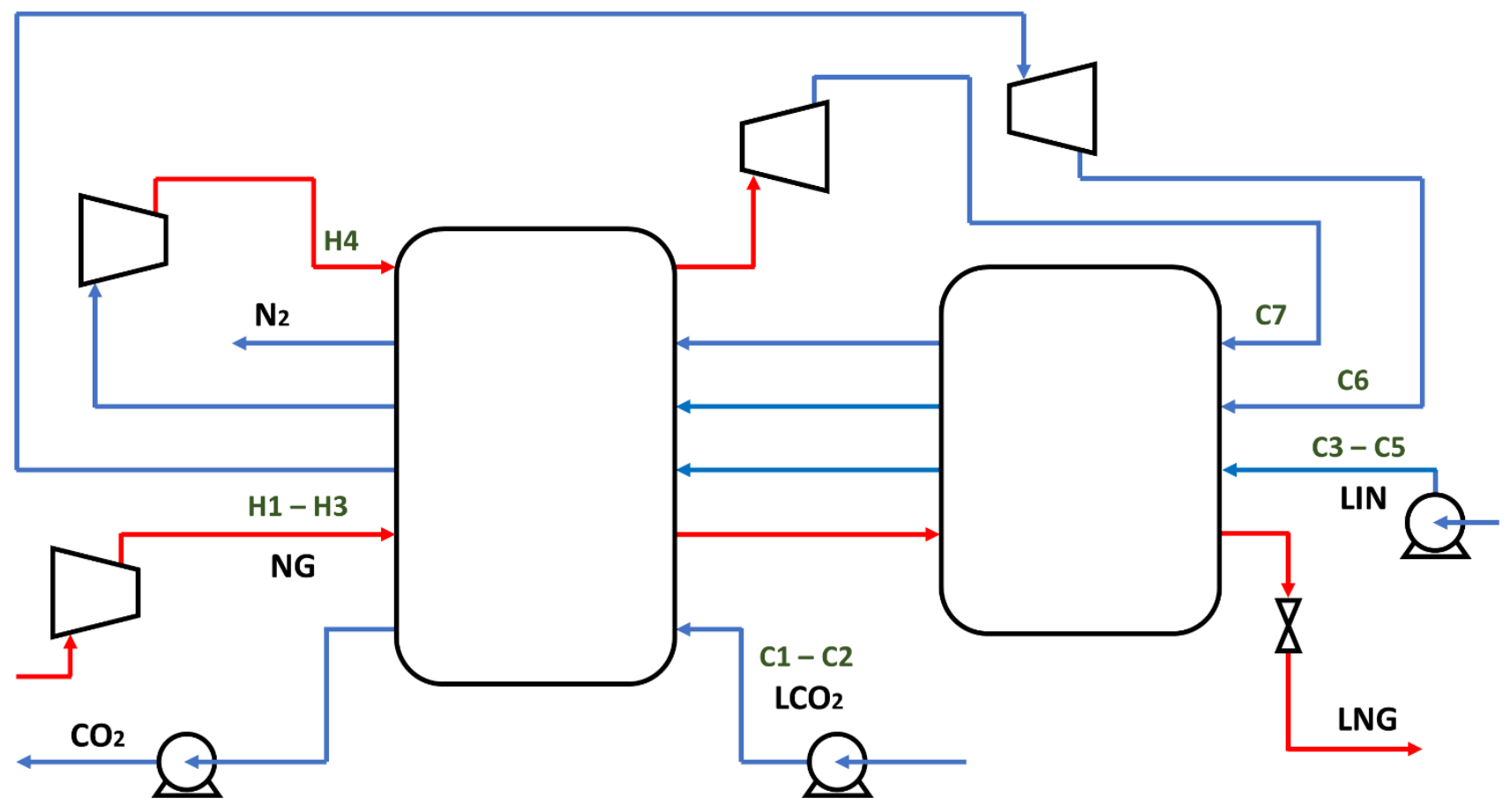

Fig. 2. Process flow diagram for the offshore LNG process after the application of ExPAnD methodology. 


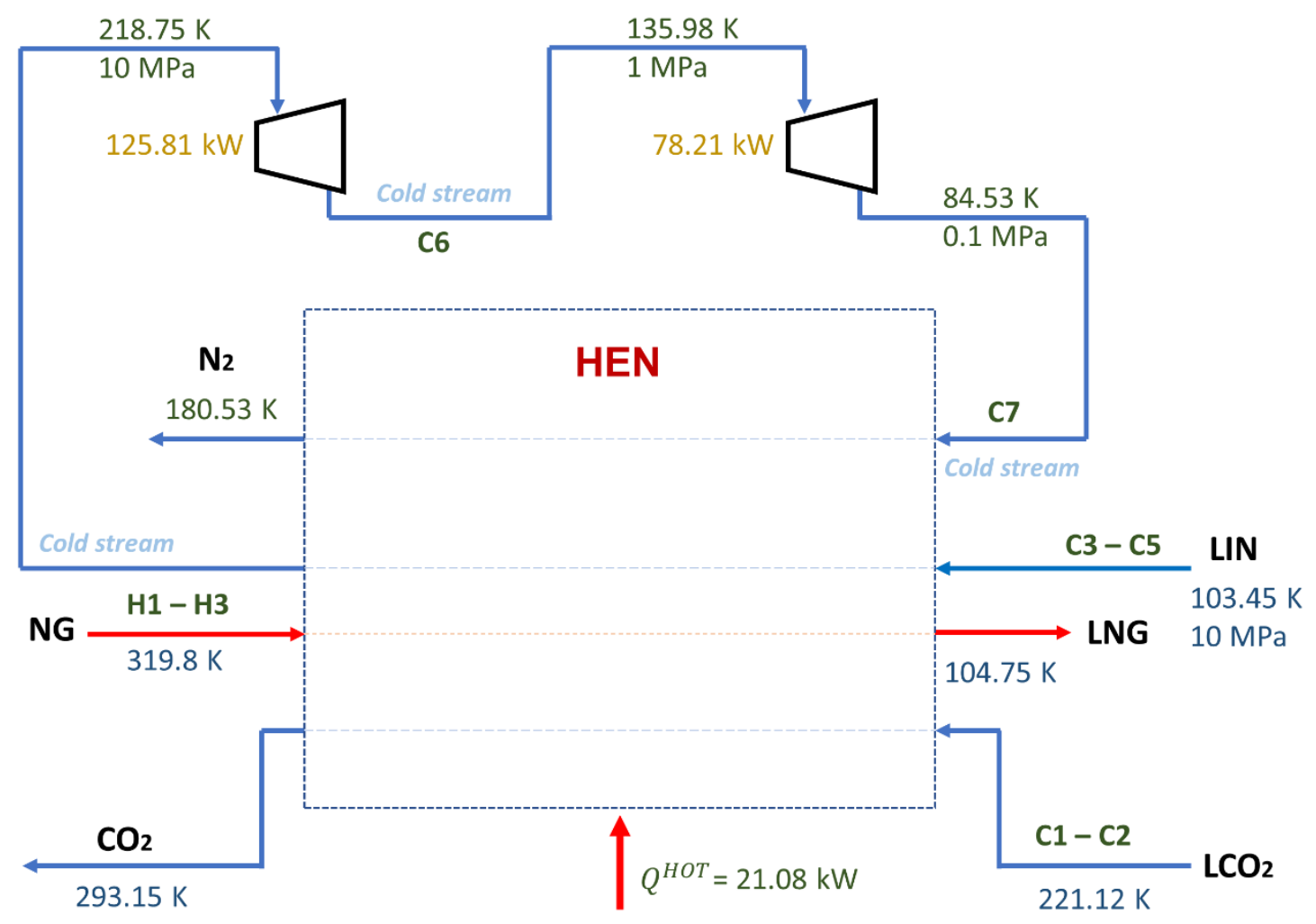

Fig. 3. Optimal configuration and main decision variables obtained for the WHEN design in Case study 1, considering the LIN stream as an unclassified process stream. 


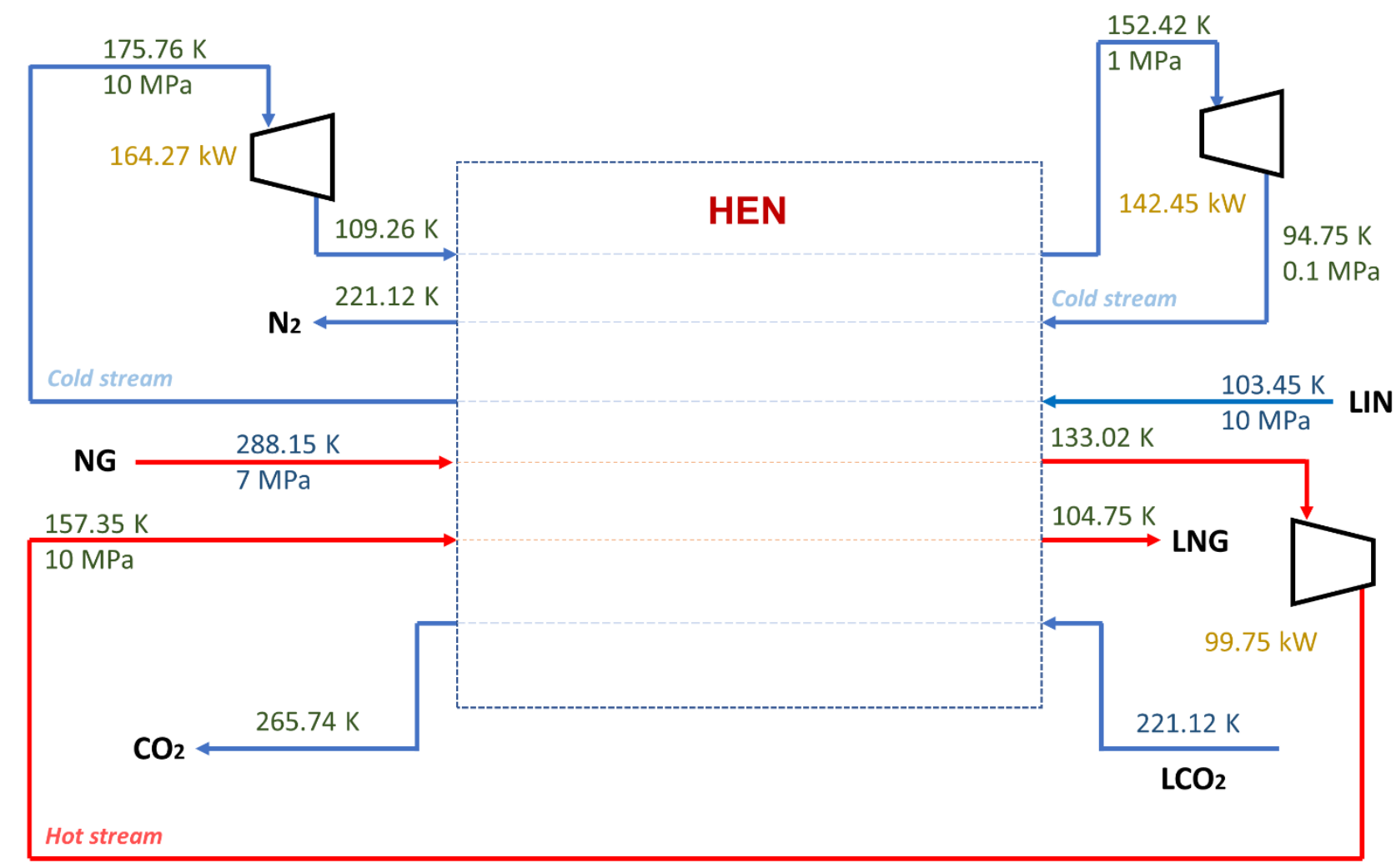

Fig. 4. Optimal configuration and main decision variables obtained for the WHEN design in Case study 1, considering both the LIN stream and 


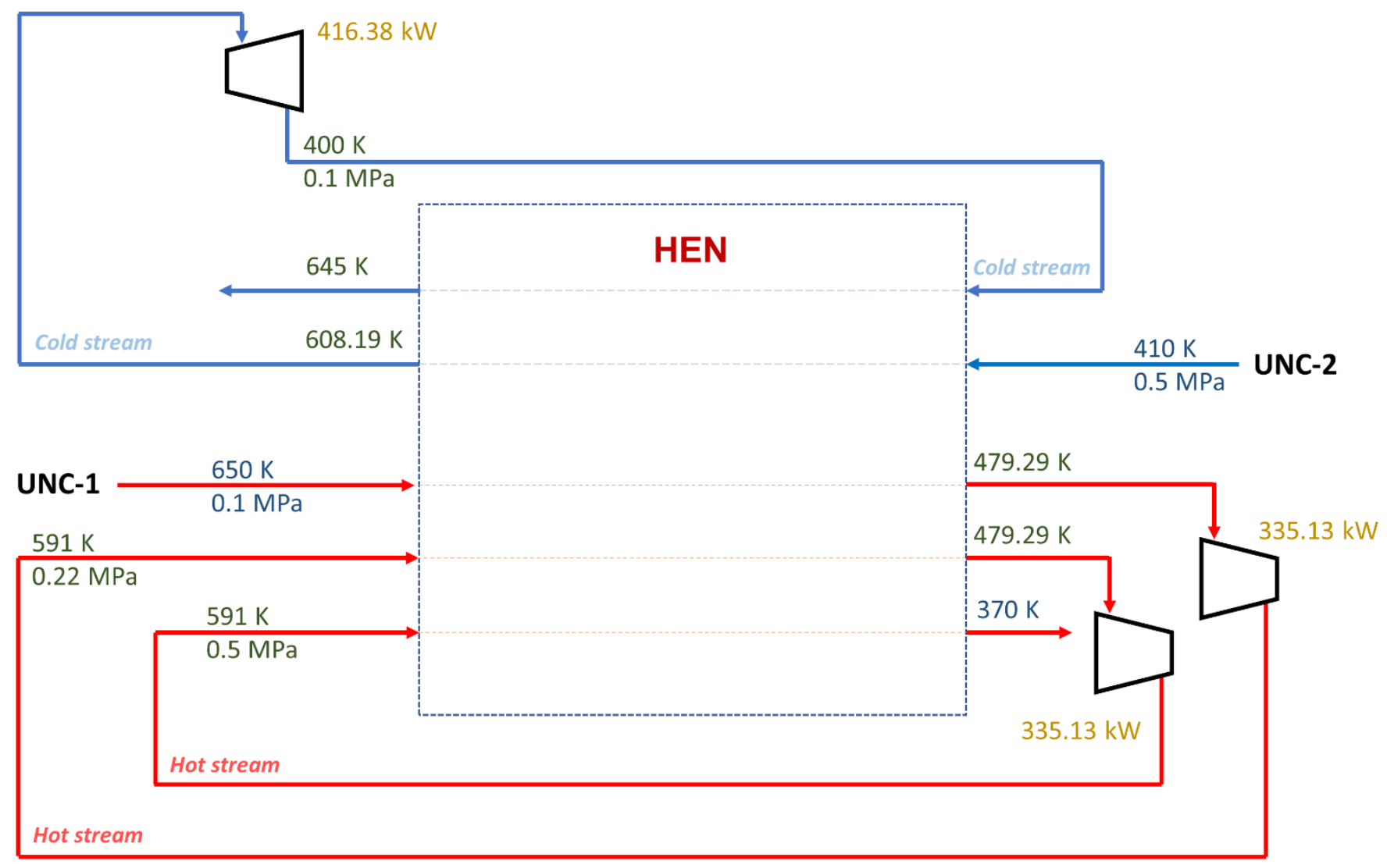

Fig. 5. Optimal configuration and main decision variables obtained for the WHEN design in Case study 2 . 


\section{Table 1}

Stream and cost data of the offshore LNG production considered for Case Study 1.

\begin{tabular}{|c|c|c|c|c|c|}
\hline Stream & $F_{s}\left(\mathrm{~kW} \mathrm{~K}^{-1}\right)$ & $T_{I N}^{S}(\mathrm{~K})$ & $\operatorname{TouT}_{s}^{S}(\mathrm{~K})$ & $P_{I N}^{S}(\mathrm{MPa})$ & $\operatorname{PoUT}_{S}^{S}(\mathrm{MPa})$ \\
\hline NG - H1 & 3.46 & 319.80 & 265.15 & 10 & 10 \\
\hline NG - H2 & 5.14 & 265.15 & 197.35 & 10 & 10 \\
\hline NG - H3 & 3.51 & 197.35 & 104.75 & 10 & 10 \\
\hline $\mathrm{LCO}_{2}-\mathrm{C} 1$ & 5.19 & 221.12 & 252.55 & 6 & 6 \\
\hline $\mathrm{LCO}_{2}-\mathrm{C} 2$ & 6.10 & 252.55 & 293.15 & 6 & 6 \\
\hline LIN - C3 & 3.20 & 103.45 & 171.05 & 10 & 10 \\
\hline LIN - C4 & 2.32 & 171.05 & 218.75 & 10 & 10 \\
\hline $\mathrm{LIN}-\mathrm{UNC}^{1}$ & 1.52 & 218.75 & - & 10 & 0.1 \\
\hline \multirow{2}{*}{\multicolumn{2}{|c|}{ Cost data (US\$ kWh ${ }^{-1}$ ) }} & $C^{E L E C}$ & $C^{C O L D}$ & $C^{\mathrm{HOT}}$ & \\
\hline & & 0.10 & 0.23 & 0.01 & \\
\hline
\end{tabular}

${ }^{1}$ Unclassified LIN stream (UNC) corresponds to streams C5-C7 and H4 in Figure 2 
Table 2

Stream and cost data of the above-ambient process considered for Case Study 2.

\begin{tabular}{|c|c|c|c|c|c|}
\hline Stream & $F_{s}\left(\mathrm{~kW} \mathrm{~K}^{-1}\right)$ & $T_{I N}^{S}(\mathrm{~K})$ & TouT $_{s}^{s}(\mathrm{~K})$ & $P_{I N}^{S}(\mathrm{MPa})$ & $\operatorname{PouT}_{s}^{S}(\mathrm{MPa})$ \\
\hline UNC-1 & 3.0 & 650 & 370 & 0.1 & 0.5 \\
\hline UNC-2 & 2.0 & 410 & - & 0.5 & 0.1 \\
\hline HU & - & 680 & 680 & - & - \\
\hline CU & - & 300 & 300 & - & - \\
\hline \multicolumn{6}{|c|}{ Cost data (US\$ kW year ${ }^{-1}$ ) } \\
\hline Electricity & & & 850.51 & & \\
\hline Hot utility & & & 80 & & \\
\hline Cold utility & & & 20 & & \\
\hline
\end{tabular}

